\title{
MECHANICAL PROPERTIES, AGING STABILITY AND TRANSLUCENCY OF SPEED-SINTERED ZIRCONIA FOR CHAIRSIDE RESTORATIONS
}

Stevan M. Cokic ${ }^{1}$, Jef Vleugels ${ }^{2}$, Bart Van Meerbeek ${ }^{1}$, Bernardo Camargo ${ }^{1}$, Evita Willems ${ }^{2}$, Maoyin $\mathrm{Li}^{2}$, Fei Zhang ${ }^{1,2}$

${ }^{1} \mathrm{KU}$ Leuven (University of Leuven), Department of Oral Health Sciences, BIOMAT \& UZ Leuven (University Hospitals Leuven), Dentistry, Leuven, Belgium;

${ }^{2} K U$ Leuven (University of Leuven), Department of Materials Engineering (MTM), Kasteelpark Arenberg 44, B-3001, Leuven, Belgium

Corresponding author: Prof. Dr. Bart Van Meerbeek, KU Leuven (University of Leuven), Department of Oral Health Sciences, BIOMAT, Kapucijnenvoer 7, blok a - box 7001, BE-3000 Leuven, Belgium. TEL: +32-16-337587, FAX: +32-16-337587, bart.vanmeerbeek@kuleuven.be

Key words: Monolithic zirconia; Speed sintering; Multilayer zirconia; Aging; Mechanical properties

Declarations of interest

Declarations of interest: none. 


\section{HIGHLIGHTS}

- Speed - sintering of 5Y-PSZ and 3Y-TZP zirconia ceramics revealed a similar density, microstructure, hardness, fracture toughness and average biaxial flexural strength, and hydrothermal aging resistance compared to the conventionally sintered references.

- Speed sintering of 3Y-TZP caused a decrease in translucency, while the optical properties of $5 Y$-PSZ were not affected by the sintering method

- Speed - sintering lowered the mechanical reliability of both the 3Y-TZP and 5Y-PSZ zirconia ceramics. 


\section{ABSTRACT}

Objectives: To evaluate the performance of zirconia ceramics sintered in a speed sintering induction furnace by comprehensive understanding of their optical and mechanical properties, microstructure, phase composition and aging stability, in comparison to ceramics sintered in a conventional furnace. Methods: Speed sintered (SS) Katana STMLss (Kuraray Noritake) (total thermal cycle/sintering time/dwell temperature: $30 \mathrm{~min} / 16 \mathrm{~min} / 1560^{\circ} \mathrm{C}$ ) and CEREC Zirconia (CEREC Zrss) (Dentsply Sirona) (15 $\mathrm{min} / 2 \mathrm{~min} / 1578{ }^{\circ} \mathrm{C}$ ) were compared to conventionally sintered (CS) Katana STMLcs $(6.8 \mathrm{~h} / 2$ $\left.\mathrm{h} / 1550^{\circ} \mathrm{C}\right)$ and inCoris TZI $\mathrm{cs}\left(4 \mathrm{~h} / 2 \mathrm{~h} / 1510^{\circ} \mathrm{C}\right)$. The translucency Parameter (TP) and Contrast Ratio (CR) were measured with a spectrophotometer. The chemical composition of the materials was determined by XRF and phase composition was characterized using XRD. Hydrothermal aging behavior was evaluated by measuring the tetragonal-to-monoclinic $\mathrm{ZrO}_{2}$ phase transformation after accelerated hydrothermal aging in steam at $134^{\circ} \mathrm{C}$. The indentation fracture toughness, Vickers hardness and biaxial strength of the sintered ceramics were assessed.

Results: Speed and conventionally sintered zirconia revealed similar density, microstructure, average strength and hydrothermal aging stability. Both Katana STMLss/cs 5Y-PSZ ceramics were characterized with a higher content of cubic phase $(\approx 53 \mathrm{wt} \%)$, which resulted in a higher amount of $\mathrm{Y}_{2} \mathrm{O}_{3}$ in the remaining tetragonal $\mathrm{ZrO}_{2}$ phases compared to the $3 \mathrm{Y}$-TZP CEREC $\mathrm{Zr}_{\text {ss }}$ and inCoris $\mathrm{TZI}_{\mathrm{CS}}(8 \mathrm{wt} \%$ and 20 $w t \%$, respectively). The sintering program did not affect the hydrothermal aging behavior of Katana STMLss and CEREC $Z_{\text {ss. }}$. TP of Katana STMLss (TP $\left.\approx 32\right)$ was not affected by speed sintering, while the translucency of CEREC $\mathrm{Zr}_{s S}(\mathrm{TP}=14)$ was significantly reduced. Hardness, fracture toughness and Weibull characteristic strength of Katana STMLss and CEREC Zr $_{\text {ss }}$ also reached the optimal level, but speed sintering substantially lowered their mechanical reliability.

Significance: Speed sintering of 3Y-TZP and 5Y-PSZ in a speed sintering induction oven appeared suitable for clinical applications. However, further studies should focus on improving of translucency and mechanical reliability of the speed-sintered zirconia ceramics.

Key words: Monolithic zirconia; Speed sintering; Multilayer zirconia; Aging; Mechanical properties 


\section{INTRODUCTION}

In the last decade, computer-aided design/computer-aided manufacturing (CAD/CAM) systems have transformed the fabrication of dental restorations in both dental laboratories and clinics [1]. Three different CAD/CAM approaches have been developed and introduced: (1) in office or so-called 'chairside', (2) in-lab systems and (3) centralized production in milling centers [2,3]. In contrast to inlab systems, where the production of the restoration is to some extend related to the dental laboratory, chairside fabrication allows a dentist to complete all the phases of restoration production within one single appointment, completely independent from a dental technician. One of the most popular chairside systems is the CEREC (computer assisted CERamic REConstruction, Dentsply Sirona, Bensheim, Germany) CAD/CAM system, which was introduced to the market in 1985. Even though some researchers have expressed their concern regarding the precision of the CEREC restoration marginal fit in the past, recent studies confirmed that it is possible to produce clinically long lasting restorations after the latest technological CEREC improvements [4].

So far, different ceramic and non-ceramic materials have become available for chairside CEREC CAD/CAM systems. In particular, esthetic ceramics (feldspatic and leucite reinforced ceramics), polymer-infiltrated ceramics and high-strength ceramics (lithium (di)silicate glass ceramics) or composite resins can be milled efficiently (usually in less than $20 \mathrm{~min}$ ) in their final structure without any major mechanical damage. This is crucial as only minimal post-milling processing is needed in order to complete the restoration. The fabrication process has thus been substantially shortened, so the final restoration can be fabricated and cemented in only one appointment. However, zirconia ceramics have always been a chairside CAD/CAM issue. Zirconia restorations could be CAM fabricated either by hard machining of a fully sintered zirconia block or by soft machining of a partially sintered zirconia block [5]. Hard milling of fully sintered zirconia is rather difficult and expensive due to its high strength and hardness, and longer milling times, which cause a significantly faster wear of the milling tools. For this reason, zirconia blocks are normally milled in the pre-sintered porous form by so-called soft machining. The milled restorations have to be additionally sintered to achieve full density, which usually takes 6$8 \mathrm{~h}$ including heating, cooling and dwell time; this thermal process normally takes place overnight.

The recent introduction of speed-sintering furnaces and the development of novel speed-sintering protocols have substantially shortened the sintering time of zirconia ceramics (from $6 \mathrm{~h}$ up to $10 \mathrm{~min}$ ) allowing the fabrication of zirconia restorations in only one visit. Such speed-sintering furnace (SpeedFire, Dentsply Sirona) was introduced to the market 2 years ago and has gained a high popularity among dentists in a short period. In comparison with conventional sintering furnaces, where heat is generated by electrical resistive heating elements, a SpeedFire furnace generates heat by electromagnetic induction [6]. In brief, an induction heating coil surrounds a susceptor body, which in 
turn surrounds the pre-sintered zirconia ceramics. The induction coil emanates a fluctuating induced magnetic field, which generates heat in the electroconductive susceptor body, usually composed of zirconium or graphite. More information is provided elsewhere [7]. This induction sintering method is considered to be beneficial compared to conventional sintering as high temperatures can be achieved extremely fast. The most advanced conventional sintering furnaces in air can achieve maximum heating rates of $40-70{ }^{\circ} \mathrm{C} / \mathrm{min}$ up to maximum $1800{ }^{\circ} \mathrm{C}$ using $\mathrm{MoSi}_{2}$ heating elements [7].

At the same time, the popularity of zirconia-based restorations have been rapidly increased among dentists due to their superior biocompatibility, favorable mechanical properties and promising esthetic potential [8]. Specifically, biomedical grade 3 mol\% yttria-stabilized tetragonal zirconia (3Y-TZP) is used in dentistry for fabricating dental crowns and fixed partial dentures. Since it is characterized by a high strength $(\approx 1000 \mathrm{MPa})$, it is considered a material of choice for the fabrication of long-span fixed dental prosthesis (FDP). However, the main drawback of 3Y-TZP ceramics is its high opacity, especially when placing anterior restorations next to natural teeth. One way to improve the esthetic appearance of zirconia ceramics and to mimic optical properties of natural tooth enamel is to cover the opaque zirconia with high-translucent porcelain veneering. The brittle nature of porcelain however frequently caused chipping or delamination from the zirconia framework [9]. For that reason, there is a clear trend towards monolithic zirconia restorations that could solve the problem of chipping and additionally avoid excessive tooth preparation inevitable for placement of bi-layered zirconia ceramics. Different approaches were proposed to improve the translucency. Zirconia materials with a higher $\mathrm{Y}_{2} \mathrm{O}_{3}$ content (> 4 mol\%) successfully increased the translucency but lowered the mechanical properties due to a reduction or absence of transformation toughening, restricting the usage of these materials to low stress-bearing areas.

Sintering of zirconia is considered to be a critical step in ceramic processing and has been a focus of interest of many researchers [10-12]. Previous research has already shown that changes in the sintering procedure directly influence the density and microstructure, including grain size and phase composition, which that can reflect on the mechanical and optical properties of zirconia ceramics [13]. Conventional sintering of Y-TZP ceramics usually includes slow and stable heating and cooling rates (up to $20{ }^{\circ} \mathrm{C} / \mathrm{min}$ ) to a sintering temperature of $1400-1500{ }^{\circ} \mathrm{C}$ which lasts for a couple of hours of dwell time [14]. On the other hand, speed sintering has been proposed as a potential strategy to obtain a finer microstructure by preventing grain growth by applying a fast heating rate while maintaining a high material density [15]. A recent study reported that an increased sintering temperature in combination with a decreased sintering time indeed yielded a smaller grain size and higher translucency [14]. In a different study where the samples were fast sintered by putting them in a preheated furnace at $1580^{\circ} \mathrm{C}$ for $10 \mathrm{~min}$, the flexural strength of zirconia ceramics was significantly improved [16]. So far, the main reported drawbacks of conventional rapid sintering are correlated with 
inhomogeneous densification or so-called shell densification of 3Y-TZP, which can have a negative impact on the microstructure of ceramics, consequently causing mechanical defects and lowering its mechanical and optical properties $[17,18]$.

In this respect, it has also been reported that an uneven low radial density distribution caused by a combination of cold isostatic powder compaction and non-optimized sintering protocol, can increase the hydrothermal aging susceptibility of 3Y-TZP ceramics [19]. Namely, in between 1999 and 2001, hundreds of zirconia femoral heads suffered from a catastrophic failure which led to their sale suspension and withdrawal from the market [20]. Subsequently, the femoral heads were subjected to a thorough examination revealing that the applied thermal sintering cycle of the ball-heads resulted in the presence of residual stresses and an uneven radial core density. This consequently lead to the unexpected rapid aging rate and the growth of aging-induced defects in the region of maximum tensile loading [19].

To the best of the authors' knowledge, a detailed evaluation of zirconia ceramics sintered in a CEREC SpeedFire (Dentsply Sirona) furnace is still missing. Therefore, the main objective of this study was to evaluate the performance of speed-sintered commercially available monolithic zirconia. The null hypothesis to be tested was that speed sintering would not affect the mechanical properties, microstructure, optical properties and aging behavior of monolithic dental zirconia. 


\section{MATERIALS \& METHODS}

\subsection{Experimental materials and specimen preparation}

Four commercial pre-sintered zirconia ceramics, of which two grades were indicated to be sintered conventionally ("CS"; Katana STML, Kuraray Noritake, Tokyo, Japan and inCoris TZI, Dentsply Sirona, York, PA, USA) and two additional grades ("SS"; Katana STML, 12Z, Kuraray Noritake, Tokyo, Japan and CEREC Zirconia medi S, Dentsply Sirona, York, PA, USA) following a speed-sintering protocol, were cut into plates with dimensions of approximate $15 \times 15 \times 3.5 \mathrm{~mm}$. Katana STMLss and CEREC ZR S $_{\text {sS }}$ samples were subsequently sintered in a SpeedFire furnace (Dentsply Sirona, York, USA) following the sintering program provided by the furnace manufacturer (Fig. 2). The total sintering time for Katana STML ss $_{\text {Sas }}$ $28 \mathrm{~min}$ and heating was done in 3-steps: (1) $350^{\circ} \mathrm{C} / \mathrm{min}$ up to $1300{ }^{\circ} \mathrm{C}$; (2) $150^{\circ} \mathrm{C} / \mathrm{min}$ up to $1500{ }^{\circ} \mathrm{C}$; (3) $10^{\circ} \mathrm{C} / \mathrm{min}$ up to $1560^{\circ} \mathrm{C}$. The dwell time at $1560^{\circ} \mathrm{C}$ lasted for $16 \mathrm{~min}$, after which the samples were cooled at $170^{\circ} \mathrm{C} / \mathrm{min}$ to $1200^{\circ} \mathrm{C}$ in a closed furnace and at $480^{\circ} \mathrm{C} / \mathrm{min}$ to room temperature by opening the furnace. The sintering program for CEREC $\mathrm{Zr}_{\text {ss }}$ started with a heating rate of $330^{\circ} \mathrm{C} / \mathrm{min}$ up to $1050^{\circ} \mathrm{C}$ and continued with the rate of $150^{\circ} \mathrm{C} / \mathrm{min}$ until the sintering temperature of $1580^{\circ} \mathrm{C}$. After 3 min dwell at $1580^{\circ} \mathrm{C}$, the samples were cooled down at $175{ }^{\circ} \mathrm{C} / \mathrm{min}$ to $1200^{\circ} \mathrm{C}$ and at $400{ }^{\circ} \mathrm{C} / \mathrm{min}$ to room temperature. On the other hand, Katana STMLcs (total sintering time: $6.8 \mathrm{~h}$; dwell time: $2 \mathrm{~h}$ at $1550{ }^{\circ} \mathrm{C}$ ) and inCoris TZI (total sintering time: $4 \mathrm{~h}$; dwell time: $2 \mathrm{~h}$ at $1510{ }^{\circ} \mathrm{C}$ ), indicated only for conventional sintering, were sintered in a conventional furnace (Nabertherm, Lilienthal, Germany), following the instructions of the respective material manufacturers. Details on the thermal cycles are provided in Fig. 2. Both Katana STMLcs and Katana STMLss are multilayered, while CEREC Zrss and inCoris $\mathrm{TZI}_{\mathrm{cS}}$ are monolayer materials with the same A2 color grade.

The sintered materials were ground parallel and gradually polished down to $1 \mu \mathrm{m}$ with diamond suspensions and with colloidal silica until a mirror surface was achieved. The final sample size was 12 $\times 12 \times 0.5 \mathrm{~mm}$ for evaluating density, microstructure, optical properties and hydrothermal aging, and $12 \times 12 \times 1.2 \mathrm{~mm}$ for analyzing biaxial flexural strength, hardness and toughness (Fig. 1).

\subsection{Chemical, phase and microstructural characterization}

The chemical composition of the zirconia grades was evaluated by wavelength dispersive X-ray fluorescence spectroscopy (WD-XRF; Bruker S8 Tiger, Germany) using a 4 kW X-ray tube. The raw data of the chemical composition of the sample were automatically provided using Quant-Express software (Bruker, Karlsruhe, Germany).

The density of the sintered ceramics $(n=6)$ was determined according to the Archimedes principle in ethanol.

Phase identification was performed by X-ray diffraction (XRD; $3003 \mathrm{~T} / \mathrm{T}$, Seifert, Ahrensburg, Germany). Mirror-polished surfaces of each material were scanned using $\mathrm{Cu} \mathrm{K}_{\alpha}(40 \mathrm{kV}, 40 \mathrm{~mA})$ from 20 
to $90^{\circ}(2 \theta)$ with the step size of $0.01^{\circ}$ for $3 \mathrm{~s}$. Rietveld analysis was used to assess the phase composition and lattice parameters using TOPAS academic V5 software (BRUKER AXS, Karlsruhe, Germany). The $\mathrm{Y}_{2} \mathrm{O}_{3}$ content in the tetragonal $\mathrm{ZrO}_{2}$ phase was calculated based on the $a$ and $c$ unit cell parameter of the tetragonal $\mathrm{ZrO}_{2}$ phase, as explained by Yamashita et al. and Gibson et al. [21,22].

The microstructure of the ceramics zirconia was characterized using scanning electron microscopy (SEM; Philips XL-30 FEG, Eindhoven, The Netherlands). Prior to analysis, the samples were mirror polished and thermally etched $\left(1250{ }^{\circ} \mathrm{C}\right)$ to reveal the grain boundary network and Pt coated. Secondary electron (SE) images were acquired at $10^{-5} \mathrm{mbar}$ pressure, an acceleration voltage of $10 \mathrm{kV}$ and $144 \mu \mathrm{A}$ beam current. The zirconia grain size of at least 1000 grains was measured on SE micrographs using Image-Pro PLUS 6.0 software (Media Cybernetics, Rockville Pike, USA) according to the linear intercept method [23]. The average grain size with standard deviation and grain-size distributions were reported without any corrections.

\subsection{Low-temperature degradation}

In vitro hydrothermal aging was performed following ISO standard 13356. Double-sided mirrorpolished specimens were autoclaved at $134^{\circ} \mathrm{C}$ and 2 bar in water vapor up to $60 \mathrm{~h}$. The autoclave with specimens was placed in an oil bath in order to obtain an internal temperature of $134^{\circ} \mathrm{C}$. The amount of monoclinic $\mathrm{ZrO}_{2}$ phase was determined using XRD (Seifert $3003 \mathrm{~T} / \mathrm{T}$, Seifert) at $40 \mathrm{kV}$ and $40 \mathrm{~mA}$ of $\mathrm{Cu}-\mathrm{K}_{\alpha}$ radiation. XRD patterns were recorded in the range of $27-33^{\circ}(2 \theta)$ in the $\theta-2 \theta$ mode with a scan speed of $2 \mathrm{~s} /$ step and a scan step of $0.02^{\circ}$ (the maximum X-ray penetration depth was calculated to be $7.5 \mu \mathrm{m}\left(\mathrm{Cu} \mathrm{K} \mathrm{K}_{\alpha}\right.$ with $98 \%$ absorption)). The surface monoclinic phase $\left(V_{m}\right)$ content was calculated using the formula of Garvie et al. [24] and Toraya [25]:

$$
V_{m}=\frac{1.311 \times\left(I_{m}^{-111}+I_{m}^{111}\right)}{1.311 \times\left(I_{m}^{-111}+I_{m}^{111}\right)+I_{t}^{101}}
$$

with I representing the intensity of monoclinic (-111 and 111) and tetragonal (101) phase peaks indicated by the subscripts $m$ and $t$. For each curve, two specimens (four exposed surfaces) were evaluated and the average value was reported.

\subsection{Optical property characterization}

The translucency of the ceramics was measured on a double-sided mirror-polished plate specimens ( $\mathrm{n}$ $=7$, thickness $=0.5 \mathrm{~mm}$ ) using a spectrophotometer (SpectroShadeTM MICRO, MHT Optic Research, Niederhasli, Switzerland) before and after $60 \mathrm{~h}$ of hydrothermal aging. Lithium-(di)silicate glassceramic $\left(L_{2}\right)$ samples $(n=7$, thickness $=0.5 \mathrm{~mm}$ ) were fabricated from IPS e. max CAD HT block (Ivoclar 
Vivadent, Schaan, Liechtenstein; "HT" = high translucency) as translucency reference control. The spectrometer was used to record the CIELAB coordinates ( $L^{*}, a^{*}$ and $\left.b^{*}\right)$ from the specimens positioned on a black and white background. A thin layer of vaseline was put in-between specimen and background for better optical contact. The translucency parameter (TP) was calculated according to:

$$
T P=\sqrt{\left(L_{B}^{*}-L_{W}^{*}\right)^{2}+\left(a_{B}^{*}-a_{W}^{*}\right)^{2}+\left(b_{B}^{*}-B_{W}^{*}\right)^{2}}
$$

with subscripts $B$ and $W$ representing the coordinates over a black and white background, respectively.

The spectral reflectance $(\mathrm{Y})$, obtained from the $L^{*}$ values, over black and white backgrounds were additionally used to calculate the contrast ratio (CR) following equation [26]:

$$
\mathrm{CR}=\frac{Y_{b}}{Y_{w}}
$$

CR linearly correlates with TP [27]. A high TP represents high translucency and low CR, and vice versa. More specifically, CR is 0.0 for a transparent material and 1 for a completely opaque material.

\subsection{Mechanical property characterization}

The micro-hardness and fracture toughness of the mirror-polished samples were measured by the indentation method using a Vickers micro-hardness tester (Model FV-700, Future-Tech, Tokyo, Japan) with a load of $98 \mathrm{~N}$ applied for $10 \mathrm{sec}$. The indentation toughness was calculated according to the Anstis equation with an E-modulus of $210 \mathrm{GPa}$ [28]. For each ceramic grade, 10 indentations were made.

The biaxial flexural strength was determined by performing piston-on-3-balls (P3B) testing on mirror-polished ceramic samples $(12 \times 12 \times 1.2 \mathrm{~mm})$ according to the ISO standard $6872(\mathrm{n}=20)$ [29]. All tests were conducted using a universal machine (Instron 4467, Norwood, MA, USA) at a crosshead speed of $0.5 \mathrm{~mm} / \mathrm{min}$. After fracture, all fragments were carefully collected and their amount was registered. The biaxial flexural strength of square samples was calculated as indicated in the ISO standard 6872 for disks, with the specimen radius replaced by half of the sample side length [30]. Therefore, the biaxial flexural strength was calculated following the equations:

$$
\begin{gathered}
\sigma=-0.2387 P(X-Y) / b^{2} \\
X=(1+v) \ln \left(\frac{r_{2}}{l}\right)^{2}+\left[\frac{(1-v)}{2}\right]\left(\frac{r_{2}}{l}\right)^{2} \\
Y=(1+v)\left[1+\ln \left(\frac{r_{1}}{l}\right)^{2}\right]+(1-v)\left(\frac{r_{1}}{l}\right)^{2}
\end{gathered}
$$


where $\sigma$ is the maximum center tensile stress, $P$ is the total load causing fracture (in N), $v$ is the Poisson's ratio, $r_{1}$ is the radius of the support circle, $r_{2}$ is the radius of the loaded area, $I$ is half of the sample side length and $b$ is the specimen thickness.

\subsection{Statistical analysis}

Grain size, translucency and biaxial strength of different materials were analyzed using one way analysis of variance (ANOVA) followed by post-hoc Tukey or Games-Howell test for multiple comparisons. Differences were considered statistically significant if $p<0.05$. All statistical analysis were performed using SPSS statistical software (SPSS, Version 20, Chicago, IL, USA). 


\section{RESULTS}

\subsection{Density measurements}

The density of the tested materials is reported in Table 1. The zirconia ceramics Katana STMLss and CEREC $Z r_{\text {ss }}$ revealed a density of $6.03 \pm 0.01 \mathrm{~g} / \mathrm{cm}^{3}$ and $6.06 \pm 0.02 \mathrm{~g} / \mathrm{cm}^{3}$ respectively which was statistically similar as that of the conventionally sintered Katana STMLcs $\left(6.03 \pm 0.01 \mathrm{~g} / \mathrm{cm}^{3}\right)$ and inCoris $\operatorname{TZI}_{\mathrm{cs}}\left(6.09 \pm 0.02 \mathrm{~g} / \mathrm{cm}^{3}\right)$.

\subsection{Chemical, phase and microstructural characterization}

The chemical characterization of the tested materials is presented in Table 2. Katana STMLss had a similar composition as its conventionally sintered control Katana STML Ls. The amount of $\mathrm{Y}_{2} \mathrm{O}_{3}$ in both Katana materials was between 8.9 and $9.04 \mathrm{wt} \%$ ( $\approx 5 \mathrm{~mol} \%)$, characterizing them as a 5 mol\% yttriastabilized zirconia (5Y-PSZ). Apart from the $\mathrm{HfO}_{2}$ impurity in all $\mathrm{ZrO}_{2}$ grades, a small amount of $\mathrm{MgO}$ $(0.15 \mathrm{wt} \%)$ was found in the conventionally sintered Katana STML $\mathrm{LS}_{\mathrm{s}}$. On the other hand, CEREC $\mathrm{Zr}_{\mathrm{ss}}$ and inCoris TZI cs contained 4.89 wt\% and 5.5 wt\% of $\mathrm{Y}_{2} \mathrm{O}_{3}$, respectively, which corresponds to a 3 mol\% yttria-stabilized tetragonal zirconia polycrystalline ceramic (3Y-TZP). $\mathrm{Er}_{2} \mathrm{O}_{3}$ was found as coloring agent in both 3Y-TZP materials, whereas CEREC Zrss, also contained a small amount of $\mathrm{Fe}_{2} \mathrm{O}_{3}$.

XRD patterns reflecting the zirconia phase composition in each zirconia ceramic are shown in Fig. 3. Katana STMLss and Katana STMLcs as well as CEREC Z $r_{\text {ss }}$ and inCoris TZI cs $_{\text {s }}$ displayed similar XRD patterns, proving that Katana STML $L_{c s}$ and inCoris $\mathrm{TZI}_{\mathrm{cs}}$ were suitable references for the tested materials. Monoclinic $\mathrm{ZrO}_{2}$ phase peaks were not present in any of the XRD patterns. Rietveld analysis (Table 3) revealed the same amount of cubic zirconia $\left(c-\mathrm{ZrO}_{2}\right)$ for Katana STMLss $(53 \pm 4 \mathrm{wt} \%)$ and its reference Katana STML $\mathrm{CS}_{\mathrm{S}}(53 \pm 2 \mathrm{wt} \%)$. CEREC $\mathrm{Zr}_{\text {sS }}$ and inCoris $\mathrm{TZI}_{\mathrm{CS}}$ showed lower amounts of $c-\mathrm{ZrO}_{2}(8 \pm 0.5 \mathrm{wt} \%$ and $20 \pm 1 \mathrm{wt} \%$, respectively). The $\mathrm{Y}_{2} \mathrm{O}_{3}$ content in the residual tetragonal $\mathrm{ZrO}_{2}$ phase was comparable and highest in Katana STML $s$ s $(4.5 \pm 0.02$ mol\%) and Katana STMLcs $(4.2 \pm 0.1$ mol\%). A substantially lower amount of $\mathrm{Y}_{2} \mathrm{O}_{3}$ was measured for CEREC Zrss and inCoris TZI $\mathrm{TS}_{\text {CS }}(3.2 \pm 0.04 \mathrm{~mol} \%$ and $2.7 \pm 0.01$ mol\%, respectively). The tetragonality $(c / a \sqrt{2})$ in the remaining tetragonal phase was lower in speedsintered Katana STMLss and CEREC Zr $r_{s S}(1.0104 \pm 0.0001$ and $1.0139 \pm 0.0001$, respectively) compared

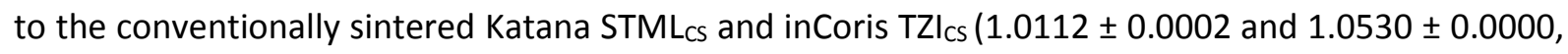
respectively).

The results of the SEM microstructural analysis are presented in Fig. 4. Katana STMLss was characterized with substantially larger grains $(0.96 \pm 0.55 \mu \mathrm{m})$ as compared with its reference Katana $\operatorname{STML}_{\text {CS }}(0.36 \pm 0.19 \mu \mathrm{m})$. The average grain size of CEREC $\operatorname{Zr}_{\text {sS }}(0.29 \pm 0.12 \mu \mathrm{m})$ was similar to that of inCoris $\mathrm{TZI}_{\mathrm{CS}}(0.31 \pm 0.13 \mu \mathrm{m})$. Moreover, the particle size distribution histogram of Katana STMLss 
reviled wide distribution tendency resulting in a bimodal grain-size distribution, while a unimodal grain-size distribution was observed in Katana STMLCs, CEREC Zrss and inCoris TZI Is. $_{\text {s. }}$

\subsection{Low-temperature degradation}

The monoclinic $\mathrm{ZrO}_{2}$ phase content in function of the increased hydrothermal aging time is presented in Fig. 5. Both speed-sintered zirconia ceramics showed the same transformation curves as their conventionally sintered references. Katana STMLss and conventionally sintered Katana STMLCS revealed no transformation up to $60 \mathrm{~h}$ of hydrothermal aging at $134{ }^{\circ} \mathrm{C}$. Cerec $\mathrm{Zr}_{\text {ss }}$ and inCoris $\mathrm{TZI}_{\mathrm{CS}}$ reviled a significant phase transformation already starting after a short aging period of $2 \mathrm{~h}$. The saturation value for Cerec $\mathrm{Zr}_{\text {ss }}$ is higher than for inCoris $\mathrm{TZI}_{\mathrm{CS}}$, which in perfect agreement with the lower $\mathrm{c}-\mathrm{ZrO}_{2}$ phase content in Cerec $\mathrm{Zr}_{\text {ss }}$ (see Table 3).

\subsection{Optical properties characterization}

TP of the zirconia ceramics before and after hydrothermal aging is presented in Fig. 6. Katana STMLss and Katana STMLcs revealed a higher TP compared with the 3Y-TZP ceramics CEREC Z $r_{s s}$ and inCoris $\mathrm{TZI}_{\mathrm{cS}}$. Moreover, the speed-sintered CEREC $\mathrm{Zr}_{\mathrm{sS}}(\mathrm{TP}=15)$ had a lower TP than the conventionally sintered inCoris TZI $c$, while the TP of the Katana zirconia ceramics were not influenced by the type of sintering process employed. Nonetheless, the TP of lithium (di)silicate glass ceramics was still significantly higher compared to the investigated zirconia ceramics. The low-temperature degradation during $60 \mathrm{~h}$ significantly decreased the TP of the tested 3Y-TZP (CEREC Z $\mathrm{r}_{\text {ss }}$ and inCoris TZI $\mathrm{IS}_{\text {S }}$ ) ceramics while it had no effect on the TP of the 5Y-PSZ (Katana STMLss and Katana STMLcs) ceramics.

\subsection{Mechanical property characterization}

Vickers hardness of all groups ranged between $1330-1350 \mathrm{~kg} / \mathrm{mm}^{2}$ (Fig. 7). Katana STMLss showed a statistically lower Vickers hardness compared to Katana STMLcs. On the other hand, CEREC Zrss showed a significantly higher hardness compared to its conventionally sintered reference inCoris TZIcs. The fracture toughness was higher for Cerec $\mathrm{Zr}_{\text {ss }}$ and inCoris $\mathrm{TZI}_{\mathrm{cs}}$ compared to both Katana zirconia ceramics. Moreover, the fracture toughness was significantly higher for Katana STMLss compared to its conventionally sintered control Katana STMLcs while there was no difference between speed-sintered CEREC $\mathrm{Zr}_{\text {ss }}$ and conventionally sintered inCoris $\mathrm{TZI}_{\mathrm{CS}}$.

The biaxial strength results, including the average flexural strength, characteristic strength $\left(\sigma_{0}\right)[95 \%$ C.I.] and Weibull plots are presented in Table 4 and Fig. 8. The average strength of CEREC $Z_{\text {ss }}$ and inCoris TZI ${ }_{\text {cs }}$ ceramics ranged between $918 \pm 135 \mathrm{MPa}$ and $823 \pm 95 \mathrm{MPa}$, respectively. Speed-sintered Katana STMLss and conventionally sintered Katana STML cs ceramics showed lower values between 619 $\pm 135 \mathrm{MPa}$ and $702 \pm 127 \mathrm{MPa}$, respectively (Table 4). Importantly, there was no statistical difference 
between the strength of conventionally and speed-sintered zirconia ceramics for both the 3Y-TZP (Katana STMLss and Katana STMLcs) and 5Y-PSZ (CEREC Z $r_{\text {ss }}$ and inCoris TZI $I_{c S}$ ) grades. However, speedsintering decreased the Weibull modulus of the tested zirconia ceramics. More specifically, the shape values $(\mathrm{m})$ for Katana STMLss and CEREC $\mathrm{Zr}_{\text {ss }}$ were 5.4 and 6.8, respectively, compared to their conventionally sintered references, revealing an $\mathrm{m}$ value of 6.3 for Katana STMLcs and 9.7 for inCoris TZI cs. 


\section{DISCUSSION}

The present results demonstrate that speed-sintering of zirconia ceramics in a SpeedFire furnace (Dentsply Sirona) did not affect density, phase composition, hardness, toughness and hydrothermal aging stability of both the 3Y-TZP (CEREC Zrss versus InCoris TZI IS $_{\text {) }}$ and 5Y-PSZ (Kantana STMLss versus Kantana STMLcs) zirconia grades, but it had a negative impact on the translucency and mechanical reliability. For this reason, the null hypothesis, stating that speed sintering does not affect mechanical properties, the microstructure, optical properties and aging behavior of monolithic dental zirconia can only be partially accepted.

In agreement with previous studies [31,32], the chemical composition of the tested zirconia ceramics revealed that both conventionally sintered Katana $S T M L_{c s}$ and speed-sintered Katana STMLsS contained the same amount of $\mathrm{Y}_{2} \mathrm{O}_{3}$, which is characteristic for 5 mol\% yttria partially stabilized zirconia (5Y-PSZ). On the other hand, the amount of $\mathrm{Y}_{2} \mathrm{O}_{3}$ in inCoris $\mathrm{TZI}_{\mathrm{CS}}$ and $\mathrm{CEREC} \mathrm{Zr}_{\mathrm{sS}}$ were lower, and comparable to a biomedical grade 3 mol\% yttria-stabilized tetragonal zirconia (3Y-TZP). Moreover, this finding was in part confirmed by the phase characterization, which revealed, as expected, both 5Y-PSZ speed-sintered Katana STMLss and conventionally sintered Katana STMLcs contained a significant amount of $c-\mathrm{ZrO}_{2}$ compared to the $t-\mathrm{ZrO}_{2}$ rich $3 \mathrm{Y}-\mathrm{TZP}$ (Cerec $\mathrm{Zr}_{s s}$ and inCoris $\mathrm{TZI}_{\mathrm{cs}}$ ). Speed sintering did not have any influence on the phase composition of $5 \mathrm{Y}-\mathrm{PSZ}$ and on the amount of $\mathrm{Y}_{2} \mathrm{O}_{3}$ in the tetragonal phase and its tetragonality, most likely due to the higher yttria content enabling faster diffusion. On the other hand, the phase composition of the 3Y-TZP zirconia ceramics was affected by speed sintering, as the CEREC $\mathrm{Zr}_{\text {ss }}$ contained a higher amount of $t-\mathrm{ZrO}_{2}(92.1 \%)$ compared to the conventionally sintered inCoris TZI cs (80\%). Nevertheless, both zirconia compositions remained were in the range of typical 3YTZP zirconia ceramics [33].

The impact of the sintering conditions on the microstructural development of zirconia ceramics has already extensively been studied [34]. It is well known that sintering factors such as high temperatures $\left(1400-1600{ }^{\circ} \mathrm{C}\right)$, sufficient dwell time and the steady heating and cooling period are crucial for obtaining optimal density and microstructure of zirconia ceramics $[34,35]$. In our study, both speedsintered 3Y-TZP and 5Y-PSZ showed similar full density values compared to their conventionally sintered references. This implies that high heating and cooling rates can be employed to obtain full density dental zirconia starting from pre-sintered blocks. Besides, in agreement with previous studies, 3Y-TZP zirconia showed higher density values compared to 5Y-PSZ, which could be attributed to the higher amount of higher density $t-\mathrm{ZrO}_{2}$ compared to the lower density $c-\mathrm{ZrO}_{2}$ [36]. According to earlier studies where the reported density values of zirconia ceramic was above $6.00 \mathrm{~g} / \mathrm{cm}^{3}[37,38]$, both speed-sintered Katana STMLss and CEREC $\mathrm{Zr}_{\text {ss }}$ can be considered fully dense [39]. Density measurements represent the first indicator of optimum sintering, as they indicate the presence of 
various structural defects such as pores or voids. In this context, it is important to understand that even though minimizing the presence of pores is highly beneficial, their complete avoidance is practically impossible to be achieved by conventional (pressureless) sintering [40]. During sintering, the green body will go through different sintering stages, where the continuous irregular porosity would gradually decrease by atomic diffusion until only small isolated spherical bubble pores are left inside the sintered body [41]. The elimination of this final $5 \%$ of closed pores during pressureless sintering requires a dwell time of several hours at the sintering temperature [42]. Incomplete sintering can leave a large amount of porosities and large pores in the sintered body, which could behave as critical flaws diminishing the strength of the material [40]. Thus, the main goal of achieving good mechanical properties of ceramic materials has always been to aim for maximum densification combined with minimal grain growth.

In order to control the grain size of zirconia ceramics, various approaches have been proposed. Apart from doping zirconia powder with dopants that suppress grain growth by segregation at the grain boundaries [43], the grain size can also be suppressed by modifying the heating rates during sintering [44]. Some researchers have reported speed sintering as a promising strategy for preserving a fine microstructure and preventing grain growth in the final stage of sintering [45]. In another study, conventional sintering yielded larger grains compared to so-called "super-speed" sintering, when the samples were inserted in a preheated furnace $\left(10 \mathrm{~min}\right.$ dwell time at $\left.1580{ }^{\circ} \mathrm{C}\right)$ and speed sintering $\left(99^{\circ} \mathrm{C} / \mathrm{min}, 30 \mathrm{~min}\right.$ dwell time at $1540^{\circ} \mathrm{C}$ ) [16]. Of course, it should be bared in mind that the formation of a fine microstructure can also be problematic for zirconia ceramics, as smaller $\mathrm{t}-\mathrm{ZrO}_{2}$ grains generally result in a higher phase stability with a lower transformation toughening effect, which can diminish the fracture toughness of zirconia [46]. However, speed sintering of all ceramics in general, including zirconia, could be problematic as the rapid temperature changes could cause a thermal shock, which could lead to surface-crack formation and subsequent material fracture.

Additionally, Chen and Mayo (1993) have also described the formation of a non-homogeneous but gradually dense outer shell structure due to rapid heating and low thermal conductivity of zirconia [47]. This rapid consolidation would cause the formation of a so-called core-shell structure characterized by a fully dense surface layer and high inner porosity [48]. Our SEM micrographs, on the other hand, did not reveal the presence of pores, voids or other structural defects regardless the type of sintering method, which might be regarded notably for the investigated speed sintering.

Additionally, the SEM micrographs showed the difference in grain size between conventionally and speed-sintered zirconia ceramics. While the mean grain size of the 3Y-TZP grades (CEREC $\mathrm{Zr}_{\text {ss }}$ and inCoris TZI $\mathrm{CS}_{\text {) }}$ ) was rather similar regardless of the way of sintering, the 5Y-PSZ grades (Katana STMLss) had significantly larger grains when the material was speed-sintered. The impact of sintering temperature on the growth of grains has already been vastly recognized, as the higher sintering 
temperature and longer dwell time yielded larger grains [10]. Accordingly, it is still not clear why Katana STMLss had substantially larger grains compared to its conventionally sintered reference Katana STMLcs since both materials were sintered at rather similar temperatures. A possible explanation might lie in the difference in density of the pre-sintered blocks, as both materials intended for speed sintering were approximately $3 \%$ denser compared to their conventionally sintered references.

The results of our study show that speed sintering did not influence the hydrothermal aging of both 3Y-TZP and 5Y-PSZ ceramic grades in regards of the subtle differences in hardness, phase content and microstructure. Moreover, these results agree with the previous studies, in which it was already well established that 3Y-TZP is prone to hydrothermal aging in contrast to 5Y-PSZ, which is known to be aging resistant [49]. The hydrothermal stability of 5Y-PSZ can be explained by the high amount of yttria content and non-transformable cubic phase present in both tested 5Y-PSZ, which agrees with previous studies $[33,50]$. Moreover, CEREC $Z_{\text {ss }}$ reached a higher monoclinic saturation level compared to inCoris TZI cs after $60 \mathrm{~h}$ of hydrothermal aging. These findings are consistent with our phase composition results, as CEREC $\mathrm{Zr}_{\text {ss }}$ contains a higher amount of transformable tetragonal phase than its conventionally sintered reference inCoris TZI cs.

5Y-PSZ showed higher translucency values compared to 3Y-TZP. However, speed sintering lowered the translucency of the 3Y-TZP zirconia grade CEREC $Z r_{\text {ss }}$ compared with its reference, while it did not have any effect on the translucency of the 5Y-PSZ ceramics. The low translucency is still considered to be one of the major drawbacks of conventional 3Y-TZP zirconia. The low ability of Y-TZP to transmit light does not allow to mimic a natural enamel appearance, especially if the thickness of the material exceeds $1 \mathrm{~mm}$. So far, the impact of various factors influencing the translucency of zirconia ceramics have extensively been studied [51,52]. In particular, the most significant factor that diminishes the translucency of 3Y-TZP (which is characterized with predominately tetragonal crystallography), is light scattering by birefringence at the grain boundaries or at residual pores or secondary phases like $\mathrm{Al}_{2} \mathrm{O}_{3}$ [53]. Fortunately, the dental industry succeeded to improve zirconia translucency by substantial reduction (even down to $0.05 \mathrm{wt} \%$ ) or complete elimination of light scattering of the alumina additive, by minimizing residual porosity by sintering zirconia at higher temperatures, or increasing the $\mathrm{Y}_{2} \mathrm{O}_{3}$ content and introducing more cubic phase zirconia [50].

Our results showed that prolonged hydrothermal aging could indeed decrease the translucency of aging-sensitive zirconia, as it was observed that $60 \mathrm{~h}$ of hydrothermal aging significantly decreased translucency of 3Y-TZP zirconia ceramics but did not influence the translucency of aging-resistant 5YPSZ ceramics, regardless of the employed sintering technique. Due to aging or mechanical stress, the crystal structure of Y-TZP zirconia can change from tetragonal to monoclinic phase, which is known to reduce the translucency of Y-TZP [54]. Even though both monoclinic and tetragonal crystals are 
anisotropic and birefringent, they have different optical properties. Besides the difference in the grain boundary orientation between monoclinic and tetragonal phases (crystals), monoclinic crystals are known to scatter more light [55]. Moreover, the surface phase transformation during aging results in surface alterations such as porosity, micro-cracking, higher roughness and reflection, which can all influence light transmission in zirconia ceramics $[56,57]$.

Even though there were statistical differences in hardness between speed-sintered and conventionally sintered 3Y-TZP zirconia ceramics, all values fell in the typical range of fully dense zirconia ceramics $\left(1240-1376 \mathrm{~kg} / \mathrm{mm}^{2}\right)[37,58]$. On the other hand, the fracture toughness of zirconia ceramics is highly dependent on the transformation toughening, phenomenon which is closely related to the grain size and tetragonal phase composition [59]. Therefore, it was not a surprise that the tested 3Y-TZP zirconia ceramics resulted in higher toughness values than the 5Y-PSZ ceramics. Although a statistical difference was observed between the 3Y-TZP zirconia ceramics, the fracture toughness values for both $3 Y-T Z P$ and 5Y-PSZ zirconia grades are also in accordance with previously published studies $[10,33]$.

Regarding the biaxial flexural strength, a piston-on-3-balls (P3B) test was performed. Although this set-up has already been used for some time, multiple studies have tried to validate and adjust the P3B test with respect to specimen size and geometry [30,60-62]. Minimizing the applicable specimen size is considered to be crucial as most of the ceramic CAD/CAM materials are supplied in the form of small $\mathrm{CAD} / \mathrm{CAM}$ blocks or disks intended for fabrication of small dental restorations, such as inlays, onlays or single crowns. Compared to the set-up described in ISO standard 6872, the set-up applied in this work was adjusted for testing square disk samples (length of 12-16 mm), without losing the accuracy of the tests [63]. Importantly, finite element analysis showed the same stress distribution when testing disk- and round-shaped samples using the applied test set-up, thus rendering comparable biaxial strength values by substituting the radius value of the disk-shaped specimen by half the length of the square-plate specimen [30]. As most commercial dental ceramic materials are supplied in the form of blocks, one of the main advantages of this set-up is that it allows the fabrication of samples for biaxial flexural strength testing without reshaping the sample. Another advantage of the present set-up is related to the testing of the recently introduced multilayered CAD/CAM zirconia ceramics blocks or disks. It is known that the addition of different types of pigments or coloring agents can significantly influence its microstructure, optical and mechanical properties [64]. Coloring of multilayered zirconia is usually done by pressing various layers consisting of $\mathrm{ZrO}_{2}$ powder doped with different amount of metal oxides. Since the ceramic block is gradually colored through its thickness, including all the layers in the analysis is of high importance.

Additionally, the flexural strength of both speed-sintered and conventionally sintered zirconia ceramic was evaluated using Weibull distribution analysis, which allows to predict material failure at 
any stress level by assessing the mechanical reliability of the material [65]. Speed sintering of both 3YTZP and 5Y-PSZ zirconia grades showed no differences in mean biaxial flexural strength as their conventionally sintered references. These values are also comparable with the flexural strength reported in other studies [66]. It is noteworthy that there might be a difference between the surface treatment of the samples used in this study (mirror polishing) and the ones that are usually applied in dental clinics. Even though polishing of zirconia restorations using various zirconia polishing kits is highly recommended to reduce opposing tooth wear, it is quite difficult to achieve the same level of smoothness as compared with mirror polishing performed in the laboratory. Previously, it has been widely reported that different clinical surface treatments of Y-TZP zirconia ceramics, such as machining, grinding and sandblasting, could cause phase transformation and consequently introduce compressive stress and micro-cracked layers in the zirconia (sub)surface [68]. Depending on the balance between compressive stress and the depth of surface flaws, the surface treatment can result in a decrease or increase of flexural strength and mechanical reliability of zirconia ceramics $[69,70]$. In particular, processes, such as sandblasting, are able to transform the zirconia surface; however, the length of generated micro-cracks will not largely exceed the thickness of the transformed compressive surface layer. On the other hand, high stresses developed during rough grinding can form severe cracks, which can propagate through the stress compressive layer and behave as major flaws and stress concentrators, thus significantly diminishing mean flexural strength and reliability of the material $[71,72]$. Since the focus of this work was on the effect of sintering, mirror polishing allows standardization of the test by dismissing all additional factors (such as deep scratches or defects) that could vastly influence the mechanical reliability and failure predictability of zirconia ceramics. Furthermore, in-vitro studies represent a low-cost effective tool, which is relatively easy to perform, control and interpret, and they also allow evaluation of the effect of isolated factors and prediction of material behavior [73]. The Weibull distribution analysis, however, revealed lower shape values ( $\mathrm{m}$ values) for the speed-sintered zirconia ceramics, which implies a reduced mechanical reliability. Since the strength of brittle materials, in general, is determined by the size of the major flaw in the specimen [73], the reduction in mechanical reliability might be attributed to the high heating or cooling rates imposed during speed sintering. It has already been described that a thermal shock provoked by extremely rapid cooling can generate high tensile stress at the surface and compressive stress inside the ceramic material [74]. When the tensile surface stress exceeds the strength of the material, it cause the formation of surface micro-cracks and subsequent material failure. On the other hand, the crack propagation could also be stopped by the compressive stress in the bulk before the failure, which would consequently result in low mechanical reliability of material. For this reason, more studies are necessary in order to optimize the speed-sintering protocol of Y-TZP zirconia ceramics. 


\section{CONCLUSION}

For the 5Y-PSZ and 3Y-TZP zirconia ceramics investigated (Katana STMLss and CEREC $\mathrm{Zr}_{\text {ss }}$ ), speed sintering revealed a similar density, microstructure, hardness, fracture toughness and average biaxial flexural strength, and hydrothermal aging resistance as compared to the conventionally sintered references. Irrespective of the sintering method applied, 5Y-PSZ Katana STMLss/cs had a lower fracture toughness and flexural strength than the 3Y-TZP CEREC $Z r_{\text {ss }}$ and inCoris TZI $\mathrm{CS}_{\text {cS }}$ ceramics. However, speed sintering of 3Y-TZP CEREC $\mathrm{Zr}_{\text {sS }}$ caused a decrease in translucency, while the optical properties of $5 Y$ PSZ were not affected by the sintering method. Moreover, speed sintering lowered the mechanical reliability of both the 3Y-TZP and 5Y-PSZ zirconia ceramics. Future research is needed to optimize the sintering programs in order to improve the optical properties and the mechanical reliability of speedsintered zirconia ceramics. 


\section{ACKNOWLEDGEMENTS}

This study was funded by the KU Leuven Research Fund under project C24/17/084 and the Research Foundation - Flanders (FWO-Vlaanderen) under grant GOB2618N. F. Zhang thanks the Research Foundation - Flanders (FWO-Vlaanderen) for her post-doctoral fellowship (12S8418N). We would like to thank the manufacturers for providing the commercial ceramics. We thank Mr. Nicolas Courtois (Anthogyr, France) for kindly providing us the piston-on-3-balls test jig. We thank Prof. Marleen Peumans (KU Leuven) for the translucency measurements. 


\section{REFERENCES}

[1] Grech J, Antunes E. Zirconia in dental prosthetics: a literature review. J Mater Res Technol 2019;8: 4956-4964. doi:10.1016/j.jmrt.2019.06.043.

[2] Baroudi K, Ibraheem SN. Assessment of Chair-side Computer-Aided Design and Computer-Aided Manufacturing Restorations: A Review of the Literature. J Int Oral Heal JIOH 2015;7:96-104.

[3] Mörmann W, Krejci I. Computer-designed inlays after 5 years in situ: clinical performance and scanning electron microscopic evaluation. Quintessence Int $1992 ; 23: 109-15$

[4] Fasbinder DJ. Clinical performance of chairside CAD/CAM restorations. J Am Dent Assoc 2006;137:22S-31S. doi:10.14219/jada.archive.2006.0395.

[5] Zarone F, Russo S, Sorrentino R. From porcelain-fused-to-metal to zirconia: Clinical and experimental considerations. Dent Mater 2011;27:83-96. doi:10.1016/j.dental.2010.10.024.

[6] Kim SW, Khalil KAR. High-frequency induction heat sintering of mechanically alloyed alumina-yttria-stabilized zirconia nano-bioceramics. J Am Ceram Soc 2006;89:1280-5. doi:10.1111/j.1551-2916.2005.00902.x.

[7] Maginnis S, Carden R, Szeremeta A, Paskalov G. Method of rapid sintering of ceramics. US Patent US8845951B2, September 30, 2014.

[8] Denry I, Kelly JR. State of the art of zirconia for dental applications. Dent Mater 2008;24:299-307. doi:10.1016/j.dental.2007.05.007.

[9] Raigrodski AJ, Hillstead MB, Meng GK, Chung KH. Survival and complications of zirconia-based fixed dental prostheses: A systematic review. J Prosthet Dent 2012; 107:170-7. doi:10.1016/S0022-3913(12)60051-1. 
[10] Inokoshi M, Zhang F, De Munck J, Minakuchi S, Naert I, Vleugels J, et al. Influence of sintering conditions on low-temperature degradation of dental zirconia. Dent Mater 2014;30:669-78. doi:10.1016/j.dental.2014.03.005.

[11] Ebeid K, Wille S, Hamdy A, Salah T, El-Etreby A, Kern M. Effect of changes in sintering parameters on monolithic translucent zirconia. Dent Mater 2014;30:e419-24. doi:10.1016/j.dental.2014.09.003.

[12] Sen N, Sermet IB, Cinar S. Effect of coloring and sintering on the translucency and biaxial strength of monolithic zirconia. J Prosthet Dent 2018;119:308.e1-308.e7. doi:10.1016/j.prosdent.2017.08.013.

[13] Kim MJ, Ahn JS, Kim JH, Kim HY, Kim WC. Effects of the sintering conditions of dental zirconia ceramics on the grain size and translucency. J Adv Prosthodont 2013;5:161-6. doi:10.4047/jap.2013.5.2.161.

[14] Kaizer MR, Gierthmuehlen PC, dos Santos MB, Cava SS, Zhang Y. Speed sintering translucent zirconia for chairside one-visit dental restorations: Optical, mechanical, and wear characteristics. Ceram Int 2017;43:10999-11005. doi:10.1016/j.ceramint.2017.05.141.

[15] Gómez SY, Da Silva AL, Gouvêa D, Castro RHR, Hotza D. Nanocrystalline yttria-doped zirconia sintered by fast firing. Mater Lett 2016;166:196-200. doi:10.1016/j.matlet.2015.12.042.

[16] Ersoy NM, Aydoğdu HM, Değirmenci BÜ, Çökük N, Sevimay M. The effects of sintering temperature and duration on the flexural strength and grain size of zirconia. Acta Biomater Odontol Scand 2015;1:43-50. doi:10.3109/23337931.2015.1068126.

[17] Lawson NC, Maharishi A. Strength and translucency of zirconia after high-speed sintering. J Esthet Restor Dent 2020; 32(2):219-225. doi: 10.1111/jerd.12524. 
[18] Chen DJ, Mayo MJ. Rapid rate sintering of nanocrystalline ZrO2-3 mol\% Y2O3. J Am Ceram Soc 1996;79: 906-912. doi:10.1111/j.1151-2916.1996.tb08524.x.

[19] Chevalier J, Gremillard L, Deville S. Low-Temperature Degradation of Zirconia and Implications for Biomedical Implants. Annu Rev Mater Res 2007;37:1-32. doi:10.1146/annurev.matsci.37.052506.084250.

[20] Clarke IC, Manaka M, Green DD, Williams P, Pezzotti G, Kim YH, et al. Current status of zirconia used in total hip implants. J Bone Jt Surg - Ser A 2003;85:73-84. doi:10.2106/00004623-200300004-00009.

[21] Yamashita I, Tsukuma K. Phase Separation and Hydrothermal Degradation of 3 mol\% Y2O3-ZrO2 Ceramics. J Ceram Soc Japan 2005;113:530-3.

[22] Gibson IR, Irvine JTS. Qualitative X-ray Diffraction Analysis of Metastable Tetragonal (t') Zirconia. J Am Ceram Soc 2001;84:615-8. doi:10.1111/j.11512916.2001.tb00708.x.

[23] Wurst JC, Nelson JA. Lineal Intercept Technique for Measuring Grain Size in Two-Phase Polycrystalline Ceramics. J Am Ceram Soc 1972;55: 109-109. doi:10.1111/j.11512916.1972.tb11224.x.

[24] Garvie RC, Nicholson PS. Phase Analysis in Zirconia Systems. J Am Ceram Soc 1972. doi:10.1111/j.1151-2916.1972.tb11290.x.

[25] Toraya H, Yoshimura M, Somiya S. Calibration Curve for Quantitative Analysis of the Monoclinic-Tetragonal ZrO2 System by X-Ray Diffraction. Commun Am Ceram Soc 1984:119-21. doi:10.1111/j.1151-2916.1984.tb19715.x.

[26] Nogueira AD, Della Bona A. The effect of a coupling medium on color and translucency of CAD-CAM ceramics. J Dent 2013;41:e18-23. doi:10.1016/j.jdent.2013.02.005.

[27] Johnston WM. Review of translucency determinations and applications to dental 
materials. J Esthet Restor Dent 2014;26:217-23. doi:10.1111/jerd.12112.

[28] Anstis GR, Chantikul P, Lawn BR, Marshall DB. A Critical Evaluation of Indentation Techniques for Measuring Fracture Toughness: I, Direct Crack Measurements. J Am Ceram Soc 1981;64:533-8. doi:10.1111/j.1151-2916.1981.tb10320.x.

[29] ISO 6872:2015. Dentistry - Ceramic materials. Geneva: International Organization for Standardization (ISO), 2015;1-28

[30] Da J, Fraga S, Vogel GF, May LG. Influence of the geometry of ceramic specimens on biaxial flexural strength: experimental testing and finite element analysis. Ceramica 2018;64:120-5. doi:10.1590/0366-69132018643692287.

[31] Kolakarnprasert N, Kaizer MR, Kim DK, Zhang Y. New multi-layered zirconias: Composition, microstructure and translucency. Dent Mater 2019;35:797-806. doi:10.1016/j.dental.2019.02.017.

[32] Harada K, Raigrodski AJ, Chung KH, Flinn BD, Dogan S, Mancl LA. A comparative evaluation of the translucency of zirconias and lithium disilicate for monolithic restorations. J Prosthet Dent 2016;116:257-63. doi:10.1016/j.prosdent.2015.11.019.

[33] Camposilvan E, Leone R, Gremillard L, Sorrentino R, Zarone F, Ferrari M, et al. Aging resistance, mechanical properties and translucency of different yttria-stabilized zirconia ceramics for monolithic dental crown applications. Dent Mater 2018;34:87990. doi:10.1016/j.dental.2018.03.006.

[34] Dahl P, Kaus I, Zhao Z, Johnsson M, Nygren M, Wiik K, et al. Densification and properties of zirconia prepared by three different sintering techniques. Ceram Int 2007;33:1603-10. doi:10.1016/j.ceramint.2006.07.005.

[35] Zhang F, Vanmeensel K, Inokoshi M, Batuk M, Hadermann J, Van Meerbeek B, et al. 3Y-TZP ceramics with improved hydrothermal degradation resistance and fracture 
toughness. J Eur Ceram Soc 2014;34:2453-63.

doi:10.1016/j.jeurceramsoc.2014.02.026.

[36] Antoniac IV. Handbook of bioceramics and biocomposites. $1^{\text {st }}$ ed. Springer, Germany 2016. doi:10.1007/978-3-319-12460-5.

[37] Tong H, Tanaka CB, Kaizer MR, Zhang Y. Characterization of three commercial Y-TZP ceramics produced for their High-Translucency, High-Strength and High-Surface Area. Ceram Int 2016;42:1077-85. doi:10.1016/j.ceramint.2015.09.033.

[38] Lazar DRR, Bottino MC, Özcan M, Valandro LF, Amaral R, Ussui V, et al. Y-TZP ceramic processing from coprecipitated powders: A comparative study with three commercial dental ceramics. Dent Mater 2008; 24(12):1676-85. doi:

10.1016/j.dental.2008.04.002. doi:10.1016/j.dental.2008.04.002.

[39] Sanon C, Chevalier J, Douillard T, Cattani-Lorente M, Scherrer SS, Gremillard L. A new testing protocol for zirconia dental implants. Dent Mater 2015;31:15-25. doi:10.1016/j.dental.2014.09.002.

[40] Darvell BW. Materials Science for Dentistry. $1^{\text {st }}$ ed. Elsevier Inc.; 2009. doi:10.1533/9781845696672.163.

[41] Ridge P. Sintering dense nanocrystalline ceramics without final-stage grain growth 2000;404:6-9.

[42] Eichler J, Rödel J, Eisele U, Hoffman M. Effect of grain size on mechanical properties of submicrometer 3Y-TZP: Fracture strength and hydrothermal degradation. J Am Ceram Soc 2007;90:2830-6. doi:10.1111/j.1551-2916.2007.01643.x.

[43] Matsui K, Yoshida H, Ikuhara Y. Isothermal sintering effects on phase separation and grain growth in yttria-stabilized tetragonal zirconia polycrystal. J Am Ceram Soc 2009;92:467-75. doi:10.1111/j.1551-2916.2008.02861.x. 
[44] Zhang HH, Xu YL, Wang B, Zhang X, Yang JF, Niihara K. Effects of heating rate on the microstructure and mechanical properties of rapid vacuum sintered translucent alumina. Ceram Int 2015;41:12499-503. doi:10.1016/j.ceramint.2015.05.136.

[45] Harmer MP, Brook RJ. Fast firing-microstructural benefits. J Br Ceram Soc 1981; $80: 147-48$

[46] Lawson S. Environmental degradation of zirconia ceramics. J Eur Ceram Soc 1995; 15:485-502. doi:10.1016/0955-2219(95)00035-S.

[47] Chen DJ, Mayo MJ. Densification and grain growth of ultrafine $3 \mathrm{~mol} \% \mathrm{Y} 2 \mathrm{O} 3 \mathrm{ZrO} 2$ ceramics. Nanostructured Mater 1993;2:469-478. doi:10.1016/0965-9773(93)901647.

[48] Prajzler V, Průša S, Maca K. Rapid pressure-less sintering of fine grained zirconia ceramics: Explanation and elimination of a core-shell structure. J Eur Ceram Soc 2019;39:5309-19. doi:10.1016/j.jeurceramsoc.2019.07.053.

[49] Kohorst P, Borchers L, Strempel J, Stiesch M, Hassel T, Bach FW, et al. Lowtemperature degradation of different zirconia ceramics for dental applications. Acta Biomater 2012;8:1213-20. doi:10.1016/j.actbio.2011.11.016.

[50] Zhang F, Inokoshi M, Batuk M, Hadermann J, Naert I, Van Meerbeek B, et al. Strength, toughness and aging stability of highly-translucent Y-TZP ceramics for dental restorations. Dent Mater 2016;32:e327-37. doi:10.1016/j.dental.2016.09.025.

[51] Pekkan G, Pekkan K, Bayindir BÇ, Özcan M, Karasu B. Factors affecting the translucency of monolithic zirconia ceramics: A review from materials science perspective. Dent Mater J 2019; 31;39(1):1-8. doi: 10.4012/dmj.2019-098. doi:10.4012/dmj.2019-098.

[52] Shahmiri R, Standard OC, Hart JN, Sorrell CC. Optical properties of zirconia ceramics 
for esthetic dental restorations: A systematic review. J Prosthet Dent 2018;119:36-46. doi:10.1016/j.prosdent.2017.07.009.

[53] Zhang F, Reveron H, Spies BC, Van Meerbeek B, Chevalier J. Trade-off between fracture resistance and translucency of zirconia and lithium-disilicate glass ceramics for monolithic restorations. Acta Biomater 2019;91:24-34. doi:10.1016/j.actbio.2019.04.043.

[54] Alghazzawi TF. The effect of extended aging on the optical properties of different zirconia materials. J Prosthodont Res 2017;61:305-14. doi:10.1016/j.jpor.2016.11.002.

[55] French RH, Glass SJ, Ohuchi FS, Xu YN, Ching WY. Experimental and theoretical determination of the electronic structure and optical properties of three phases of ZrO2. Phys Rev B 1994; 49:5133-5142 doi:10.1103/PhysRevB.49.5133.

[56] Lucas TJ, Lawson NC, Janowski GM, Burgess JO. Effect of grain size on the monoclinic transformation, hardness, roughness, and modulus of aged partially stabilized zirconia. Dent Mater 2015; 31:1487-92. doi: 10.1016/j.dental.2015.09.014.

[57] Fathy SM, El-Fallal AA, El-Negoly SA, El Bedawy AB. Translucency of monolithic and core zirconia after hydrothermal aging. Acta Biomater Odontol Scand 2015;1:86-92. doi:10.3109/23337931.2015.1102639.

[58] Turp V, Tuncelli B, Sen D, Goller G. Evaluation of hardness and fracture toughness, coupled with microstructural analysis, of zirconia ceramics stored in environments with different pH values. Dent Mater J 2012; 31:1487-92. doi:10.1016/j.dental.2015.09.014.

[59] Trunec M. Effect of grain size on mechanical properties of 3Y-TZP ceramics. Ceram Silikaty 2008;52:165-71. 
[60] Wendler M, Belli R, Petschelt A, Mevec D, Harrer W, Lube T, et al. Chairside CAD/CAM materials. Part 2: Flexural strength testing. Dent Mater 2017;33:99-109. doi:10.1016/j.dental.2016.10.008.

[61] Danzer R, Supancic P, Harrer W, Lube T, Borger A. Biaxial strength testing on mini specimens. Fract Nano Eng Mater Struct - Proc 16th Eur Conf Fract 2006;i:589-90. doi:10.1007/1-4020-4972-2_292.

[62] Danzer R, Supancic P, Harrer W. Biaxial tensile strength test for brittle rectangular plates. J Ceram Soc Japan 2006;114:1054-60. doi:10.2109/jcersj.114.1054.

[63] Belli R, Wendler M, Zorzin JI, Lohbauer U. Practical and theoretical considerations on the fracture toughness testing of dental restorative materials. Dent Mater 2018;34:97-119. doi:10.1016/j.dental.2017.11.016.

[64] Shah K, Holloway JA, Denry IL. Effect of Coloring with Various Metal Oxides on the Microstructure, Color, and Flexural Strength of 3Y-TZP. J Biomed Mater Res - Part B Appl Biomater 2008; 87(2):329-37. doi: 10.1002/jbm.b.31107.

[65] Nassary Zadeh P, Lümkemann N, Sener B, Eichberger M, Stawarczyk B. Flexural strength, fracture toughness and translucency of cubic/tetragonal zirconia materials. J Prosthet Dent 2018:1-7. doi:10.1016/j.prosdent.2017.12.021.

[66] Kumchai H, Juntavee $P$, Sun AF, Nathanson D. Effect of Glazing on Flexural Strength of Full-Contour Zirconia. Int J Dent 2018; 8793481. doi: 10.1155/2018/8793481.

[67] Inokoshi M, Vanmeensel K, Zhang F, De Munck J, Eliades G, Minakuchi S, et al. Aging resistance of surface-treated dental zirconia. Dent Mater 2015;31:182-94. doi:10.1016/j.dental.2014.11.018.

[68] Vila-Nova TEL, Gurgel IH, Moura DMD, Batista AUD, Zhang Y, Paskocimas CA, et al. Effect of finishing/polishing techniques and low temperature degradation on the 
surface topography, phase transformation and flexural strength of ultra-translucent ZrO2 ceramic. Dent Mater 2020:1-14. doi:10.1016/j.dental.2020.01.004.

[69] Pereira GKR, Fraga S, Montagner AF, Soares FZM, Kleverlaan CJ, Valandro LF. The effect of grinding on the mechanical behavior of Y-TZP ceramics : A systematic review and meta-analyses. J Mech Behav Biomed Mater 2016;63:417-42. doi:10.1016/j.jmbbm.2016.06.028.

[70] Měřínský K, Betko J, Morvic M, Kordoš $P$. The effect of surface grinding and sandblasting on flexural strength andreliability of Y-TZP zirconia ceramic. Solid State Electron 1968;11:187-91. doi:10.1016/0038-1101(68)90151-2.

[71] Inokoshi M, Zhang F, Vanmeensel K, De Munck J, Minakuchi S, Naert I, et al. Residual compressive surface stress increases the bending strength of dental zirconia. Dent Mater 2017;33:e147-54. doi:10.1016/j.dental.2016.12.007.

[72] Zhang F, Spies BC, Vleugels J, Reveron H, Chevalier J. High-translucent yttria-stabilized zirconia ceramics are wear-resistant and antagonist-friendly. Dent Mater 2019;12:

1776-1790. doi:10.1016/j.dental.2019.10.009.

[73] Quinn JB, Quinn GD. A practical and systematic review of Weibull statistics for reporting strengths of dental materials. Dent Mater 2010;26:135-47. doi:10.1016/j.dental.2009.09.006.

[74] Adolfsson E. Advanced Ceramics for Dentistry. $1^{\text {st }}$ ed. Elsevier Inc. 2014. doi:10.1016/B978-0-12-394619-5.00017-1. 


\section{TABLES}

Table 1. Density of sintered zirconia ceramics

\begin{tabular}{llc}
\hline & \multicolumn{2}{c}{ Density $\left(\mathrm{g} / \mathrm{cm}^{3}\right)$} \\
& Mean & SD \\
\hline Katana STMLcs & 6.03 & 0.01 \\
Katana STMLss & 6.03 & 0.01 \\
CEREC Zr rss $_{\text {inCoris TZI }}$ & 6.06 & 0.02 \\
& 6.09 & 0.02 \\
\hline
\end{tabular}


Table 2. The elemental composition of the commercial ceramics, as obtained by XRF

\begin{tabular}{lcccc}
\hline Composition (wt\%) & Katana STML & Katana STML & CEREC Zr $_{\text {sS }}$ & inCoris TZI \\
\hline $\mathrm{ZrO}_{2}$ & 89.6 & 89.7 & 93.1 & 92.4 \\
$\mathrm{Y}_{2} \mathrm{O}_{3}$ & 8.9 & 9.04 & 4.89 & 5.5 \\
$\mathrm{HfO}_{2}$ & 1.12 & 1.15 & 1.12 & 1.44 \\
$\mathrm{MgO}$ & 0.15 & $/$ & $/$ & $/$ \\
$\mathrm{Er}_{2} \mathrm{O}_{3}$ & $/$ & $/$ & 0.4 & 0.29 \\
$\mathrm{Fe}_{2} \mathrm{O}_{3}$ & $/$ & $/$ & 0.1 & $/$ \\
\hline
\end{tabular}


Table 3. Phase composition and lattice parameters, as obtained by Rietveld analysis

\begin{tabular}{|c|c|c|c|c|c|c|}
\hline & & & Katana STML $\mathrm{CS}_{\mathrm{CS}}$ & Katana STMLss & CEREC $Z_{\text {sS }}$ & inCoris TZI cs \\
\hline \multirow[t]{6}{*}{ XRD } & Tetragonal & $\begin{array}{l}\text { fraction (\%) } \\
c(\AA \AA)\end{array}$ & $\begin{array}{l}47 \pm 2 \\
5.1689+0.0007\end{array}$ & $\begin{array}{l}47 \pm 4 \\
5.1650+0.0000\end{array}$ & $\begin{array}{l}92 \pm 0.5 \\
5.1733 \pm 0.0003\end{array}$ & $\begin{array}{l}80 \pm 1 \\
5.1768+0.0004\end{array}$ \\
\hline & & $a(\AA ̊)$ & $3.6146 \pm 0.0002$ & $3.6144 \pm 0.0003$ & $3.6080 \pm 0.0002$ & $3.6055 \pm 0.0002$ \\
\hline & & $c / a \sqrt{2}$ & $1.0112 \pm 0.0002$ & $1.0104 \pm 0.0001$ & $1.0139 \pm 0.0001$ & $1.053 \pm 0$ \\
\hline & & $\mathrm{Y}_{2} \mathrm{O}_{3}(\mathrm{~mol} \%)$ & $4.2 \pm 0.1$ & $4.5 \pm 0.02$ & $3.2 \pm 0.04$ & $2.7 \pm 0.01$ \\
\hline & Cubic & fraction (\%) & $53 \pm 2$ & $53 \pm 4$ & $8 \pm 0.5$ & $20 \pm 1$ \\
\hline & & $c(\AA ̊)$ & $5.1354 \pm 0.0001$ & $5.1354 \pm 0.0003$ & $5.1429 \pm 0.0014$ & $5.1369 \pm 0.0005$ \\
\hline
\end{tabular}


Table 4. Mean biaxial flexural strength, Weibull modulus and characteristic strength of the tested zirconia ceramics

\begin{tabular}{|c|c|c|c|}
\hline & \multirow{2}{*}{$\begin{array}{c}\text { Descriptive analysis (MPa) } \\
\text { Mean } \pm \text { SD }\end{array}$} & \multicolumn{2}{|c|}{ Weibull modulus } \\
\hline & & $\mathrm{m}$ & $\sigma_{\circ}$ \\
\hline Katana STMLcs & $702 \pm 127^{a}$ & 6.3 & 754 \\
\hline Katana STMLss & $619 \pm 13^{a}$ & 5.4 & 672 \\
\hline CEREC $Z r_{\text {sS }}$ & $918 \pm 135^{b}$ & 6.8 & 977 \\
\hline inCoris TZI cs & $823 \pm 99^{b}$ & 9.7 & 865 \\
\hline
\end{tabular}


FIGURES:

Figure 1.

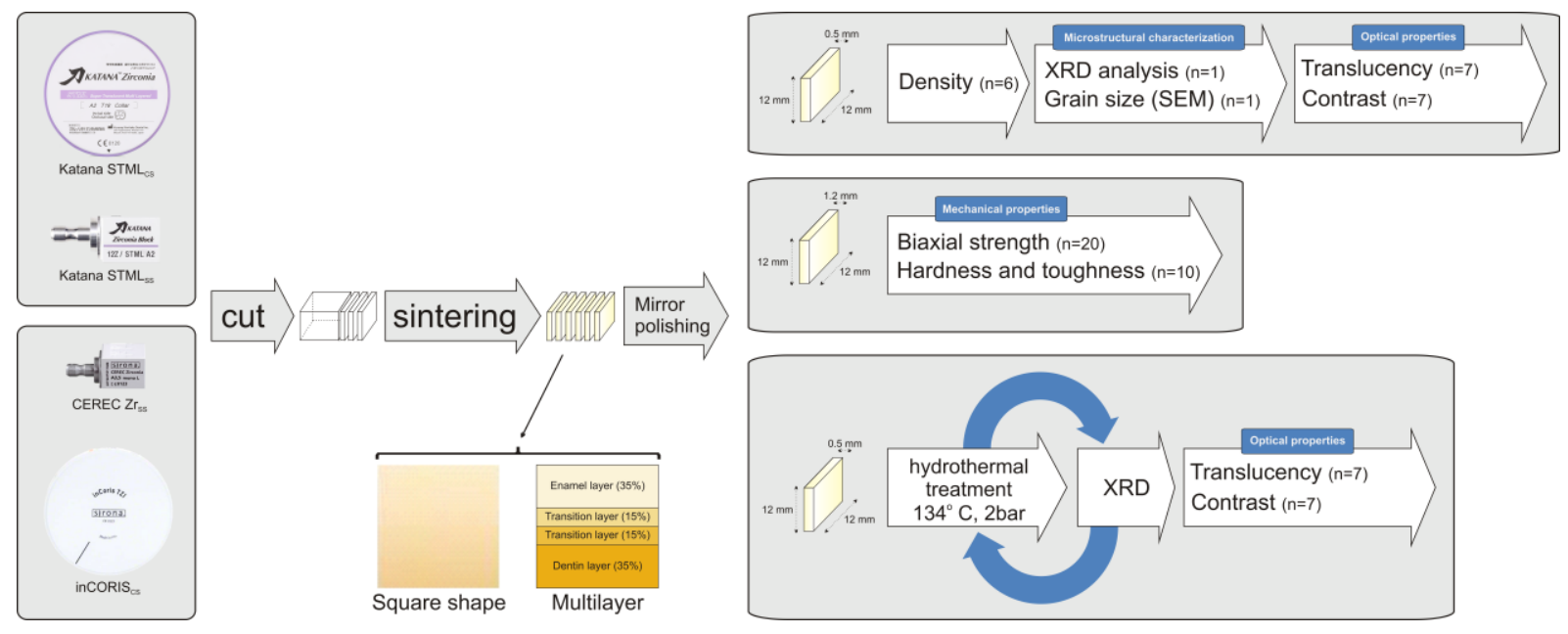


Figure 2.

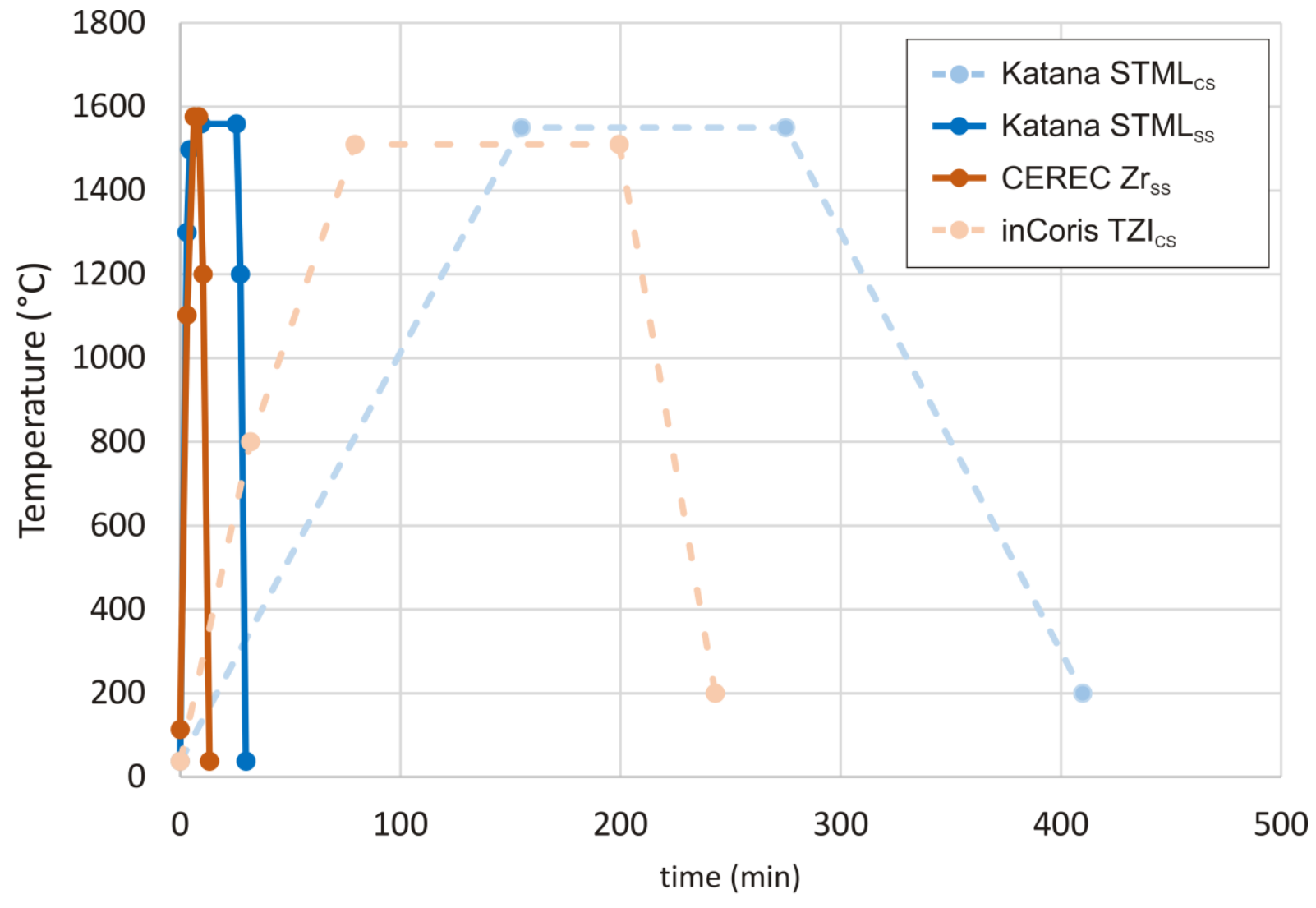

\begin{tabular}{|c|c|c|c|c|}
\hline & Katana STML $\mathrm{Cs}_{\mathrm{c}}$ & Katana STML & CEREC $\mathrm{Zr}_{\mathrm{ss}}$ & inCoris $\mathrm{TZI}_{\mathrm{cs}}$ \\
\hline $\begin{array}{l}\text { Heating rate } \\
\left({ }^{\circ} \mathrm{C} / \mathrm{min}\right)\end{array}$ & $10^{\circ} \mathrm{C} / \min \left(1550^{\circ} \mathrm{C}\right)$ & $\begin{array}{c}350^{\circ} \mathrm{C} / \min \left(1300^{\circ} \mathrm{C}\right) \\
150^{\circ} \mathrm{C} / \min \left(1500{ }^{\circ} \mathrm{C}\right) \\
10^{\circ} \mathrm{C} / \min \left(15600^{\circ} \mathrm{C}\right)\end{array}$ & $\begin{array}{l}330^{\circ} \mathrm{C} / \min \left(1050^{\circ} \mathrm{C}\right) \\
150^{\circ} \mathrm{C} / \min \left(1580^{\circ} \mathrm{C}\right)\end{array}$ & $\begin{array}{c}25^{\circ} \mathrm{C} / \min \left(800^{\circ} \mathrm{C}\right) \\
15^{\circ} \mathrm{C} / \min \left(1510^{\circ} \mathrm{C}\right)\end{array}$ \\
\hline Sintering & $1550^{\circ} \mathrm{C}$ for $120 \mathrm{~min}$ & $1560^{\circ} \mathrm{C}$ for $16 \mathrm{~min}$ & $1580^{\circ} \mathrm{C}$ for $3 \mathrm{~min}$ & $1510^{\circ} \mathrm{C}$ for $120 \mathrm{~min}$ \\
\hline $\begin{array}{l}\text { Cooling rate } \\
\left({ }^{\circ} \mathrm{C} / \mathrm{min}\right)\end{array}$ & $10^{\circ} \mathrm{C} / \min \left(200^{\circ} \mathrm{C}\right)$ & $\begin{array}{c}170^{\circ} \mathrm{C} / \min \left(1200^{\circ} \mathrm{C}\right) \\
480^{\circ} \mathrm{C} / \min \left(37^{\circ} \mathrm{C}\right)\end{array}$ & $\begin{array}{c}175^{\circ} \mathrm{C} / \min \left(1200^{\circ} \mathrm{C}\right) \\
400^{\circ} \mathrm{C} / \min \left(37^{\circ} \mathrm{C}\right)\end{array}$ & $30^{\circ} \mathrm{C} / \mathrm{min}\left(200^{\circ} \mathrm{C}\right)$ \\
\hline
\end{tabular}


Figure 3.

(a)

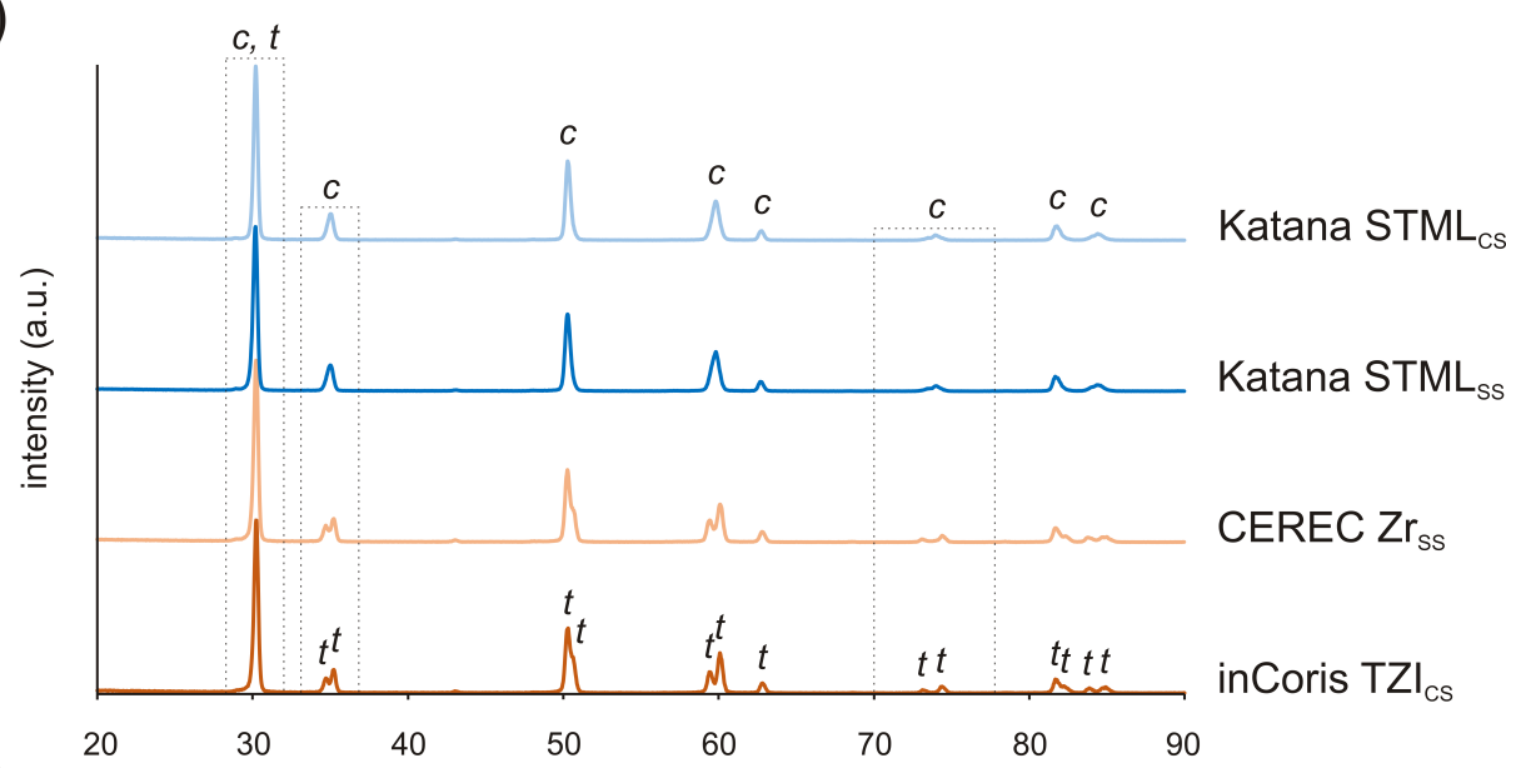

(b)
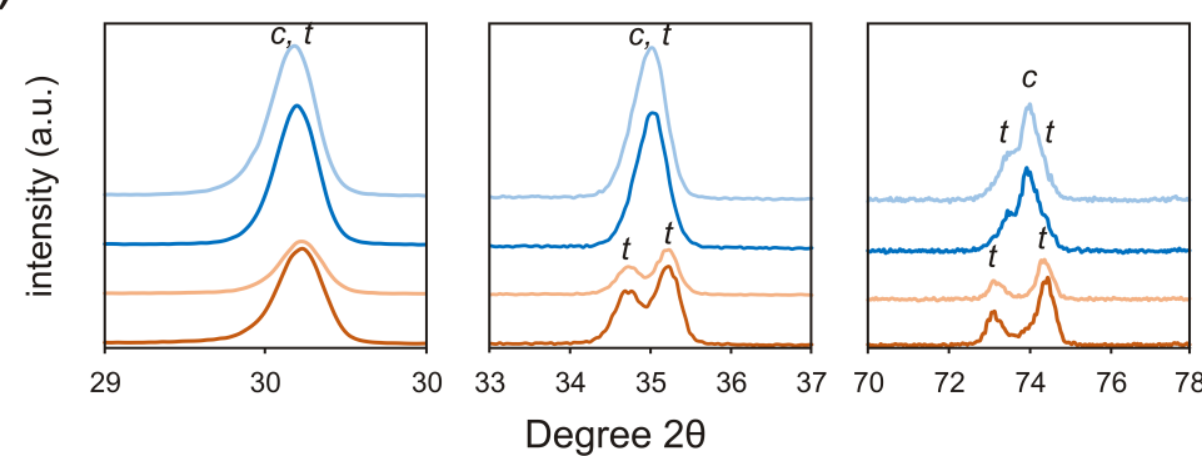

Katana STML ${ }_{c s}$

Katana $S T M L_{\text {ss }}$ CEREC $\mathrm{Zr}_{\mathrm{SS}}$ inCoris $\mathrm{TZI}_{\mathrm{CS}}$ 


\section{Figure 4.}
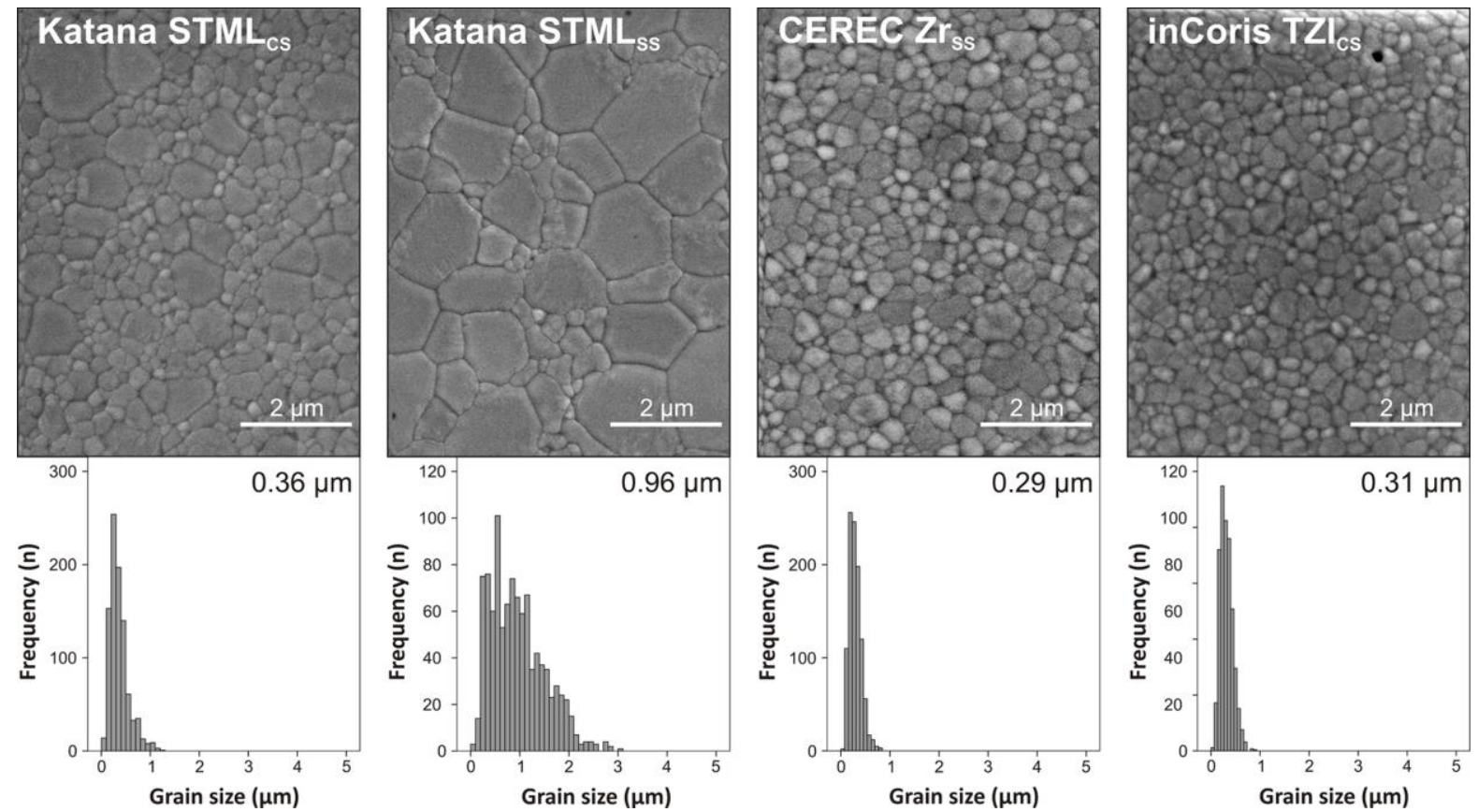
Figure 5.

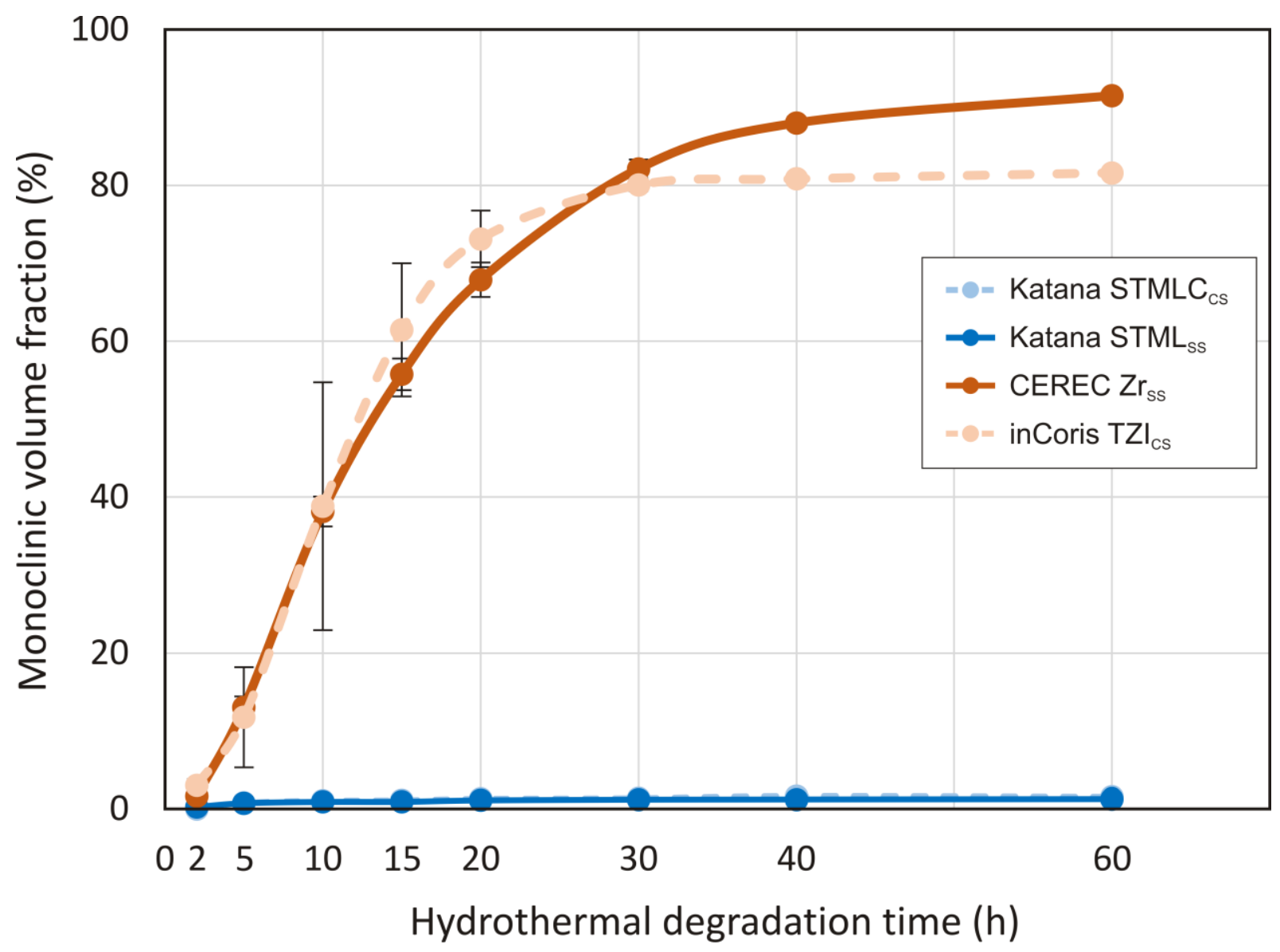


Figure 6.

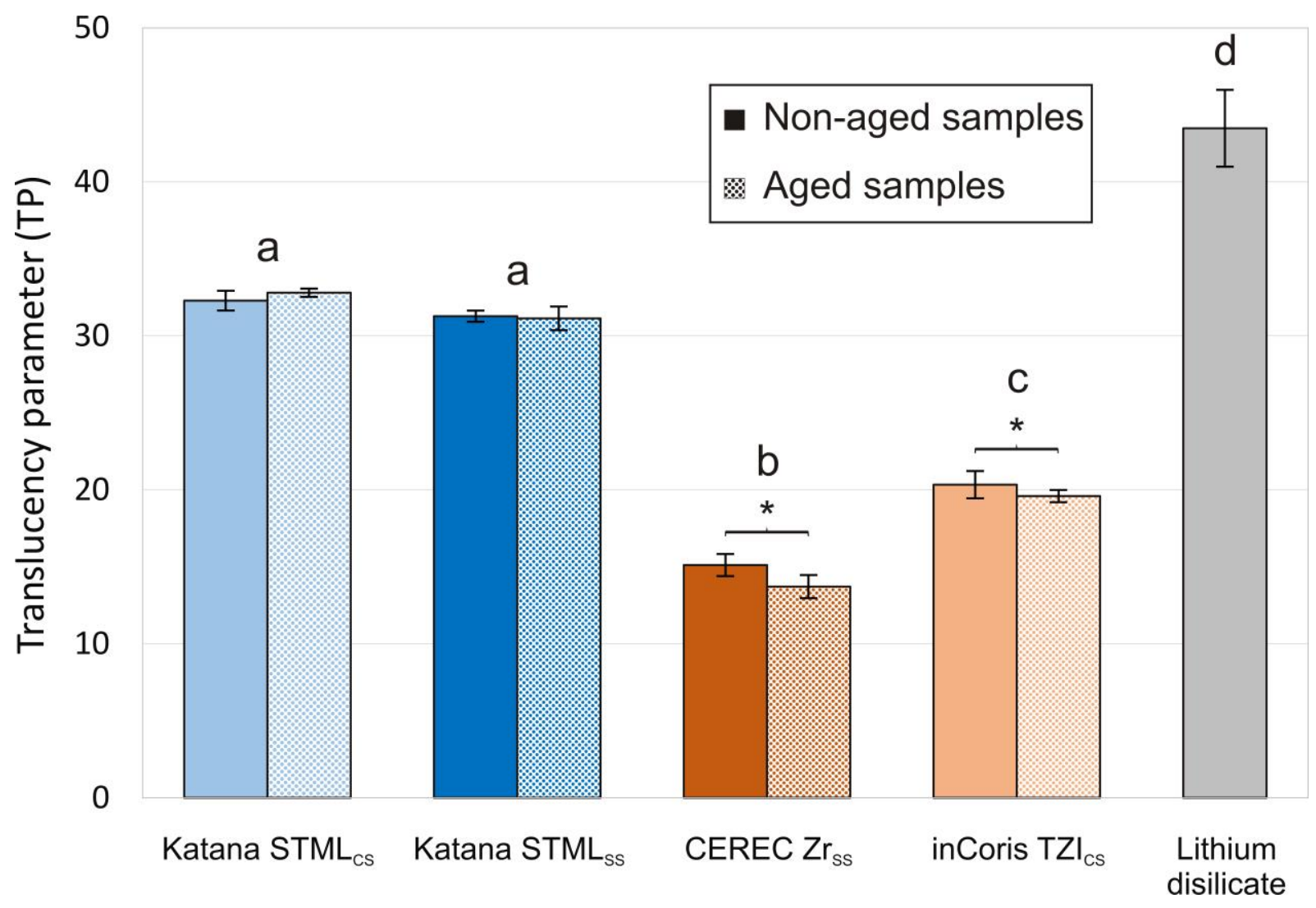


Figure 7.

(a)

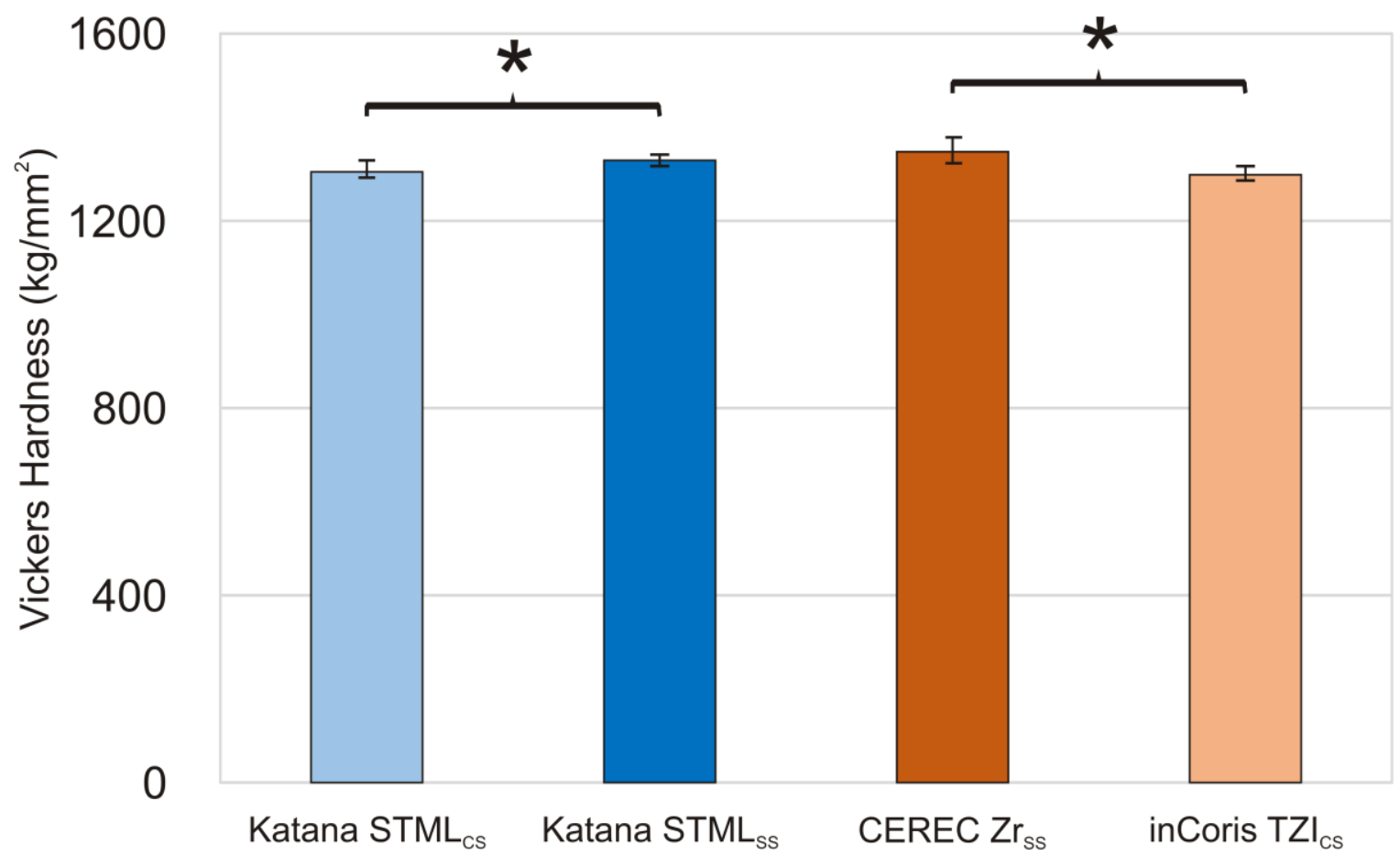

(b)

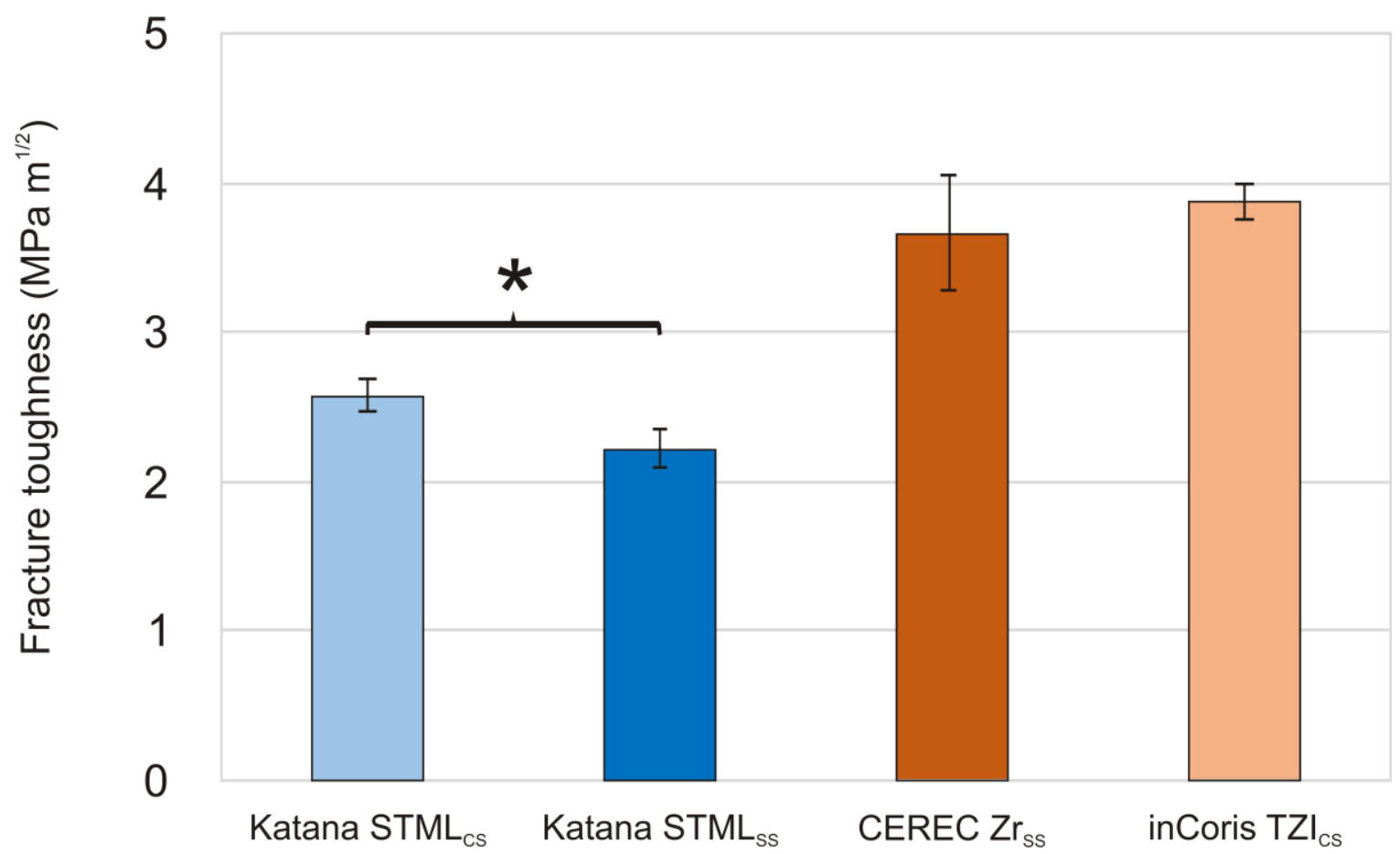


Figure 8.

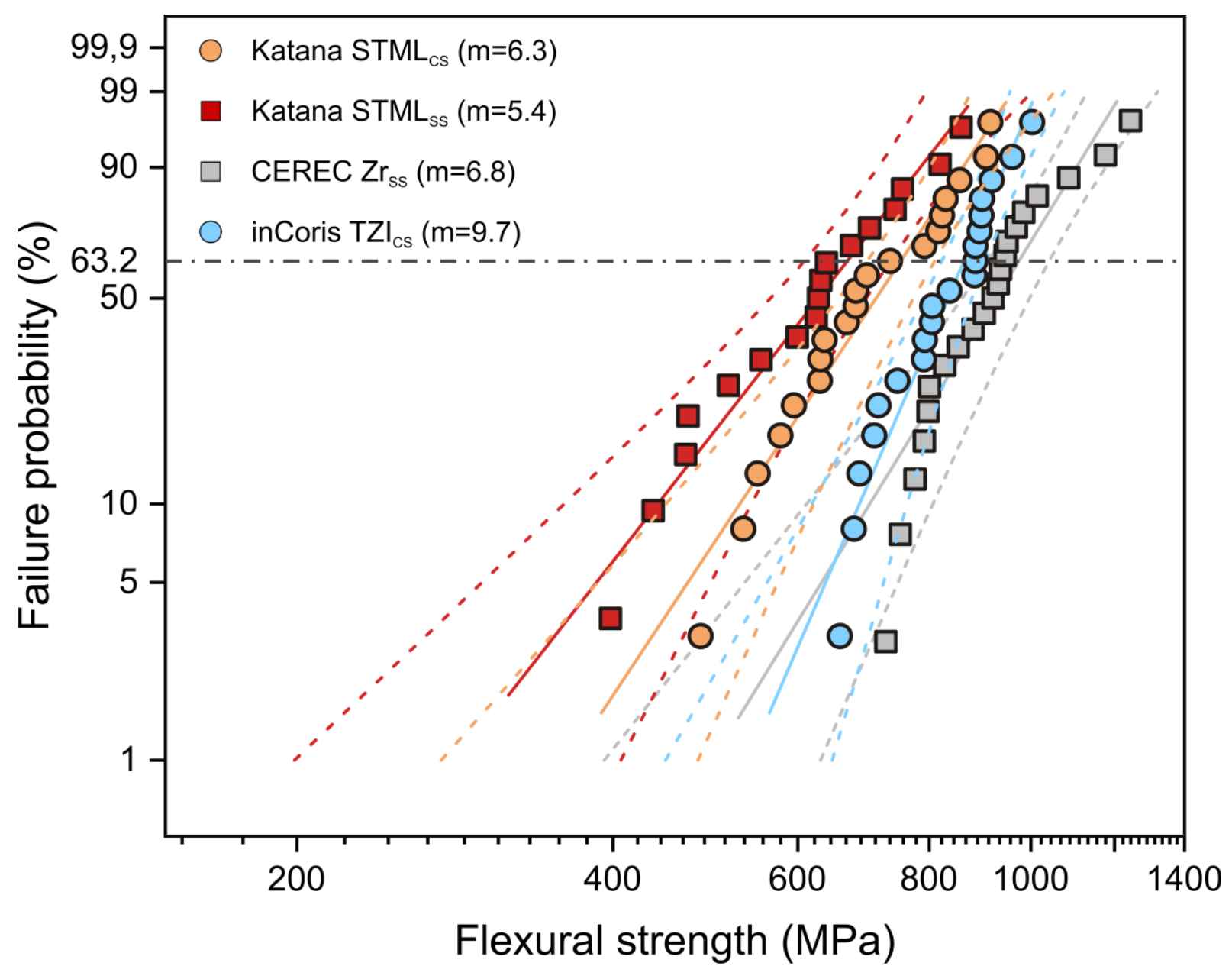




\section{FIGURE CAPTIONS:}

Fig. 1: Flow chart of the experimental study set-up

Fig. 2: Speed sintering (SS) and conventional sintering (CS) protocol as a function of temperature and time.

Fig. 3: (a) XRD patterns of the zirconia ceramics. The characteristic peaks of cubic and tetragonal zirconia are indexed in the patterns of speed-sintered and conventionally sintered zirconia ceramics. (b) Expanded view of the 29-30, 33-37 and 70-78 $2 \theta$ range.

Fig. 4: SEM micrograph of speed-sintered (Katana STMLSS and CEREC ZrSS) and conventionally sintered (Katana STMLCS and inCoris TZICS) ceramics. Katana STMLSS and Katana STMLCS had the largest average grain size of $0.96 \mu \mathrm{m}$ and $0.36 \mu \mathrm{m}$, respectively. CEREC ZrSS and inCoris TZICS have a similar average grain size of $0.29 \mu \mathrm{m}$ and $0.31 \mu \mathrm{m}$, respectively. The particle size distribution histogram of Katana STMLSS showed wide distribution tendency of a bimodal grain-size distribution, while unimodal grain-size distribution was observed in Katana STMLCS, CEREC ZrSS and inCoris TZICS.

Fig. 5: Monoclinic $\mathrm{ZrO} 2$ phase content in function of hydrothermal aging time at $134^{\circ} \mathrm{C}$ up to $60 \mathrm{~h}$.

Fig. 6: Translucency of speed-sintered and conventionally sintered materials before and after hydrothermal aging up to $60 \mathrm{~h}$. Letter annotation and asterix represent the significant difference between the tested materials and between non-aged and aged samples at the significance level $p<$ 0.05 , respectively.

Fig. 7: Vickers hardness and fracture toughness of speed-sintered and conventionally sintered zirconia ceramics.

Fig. 8: Biaxial flexural strength of speed-sintered and conventionally sintered zirconia ceramics. Weibull plot with $95 \%$ confidence bands. The horizontal dotted line represents the Weibull characteristic strength (failure probability of $63.2 \%$ ). 